\title{
إشكالية التحيز في الفكر العربي المعاصر
}

\section{غزلان هاشمي \\ جامعة محمد الثريف / الجزائر}

المقدمة :

ساهمت الكثير من التغيرات والملابسات السوسيوثقافية والسياسية في الاتجاه نحو كثف مضمرات الخطاب فالتبدل الواضح في خارطة العالم الجيوسياسي وكثرة التأزمات العالمية، لفتت الانتباه إلى أن الحقائق لا تعدو أن تكون صياغة مؤدلجة ، ففكرة الآخر للعالم الغربي له ما يبرره ،إذ طوال سنين والعالم الغربي يسعى بمؤسساته الرسمية السلطوية إلى توجيه الرأي العام، بل والعالم الإسلامي قبله ساهم في الترويج إلى تتميطات جاهزة وذلك حال كل حضارة أيام ازدهارها ،من هنا فالعديد من الأسماء الغربية والعربية وجدت أن مختلف الخطابات المنتجة تاريخيا وحتى حديثا تحمل اعتبارات أيديولوجية مهنتها طمس الحقائق ،والاتجاه ناحية النمذجة المتعالية أو صياغة الوعي العام بما يخدم المصالح الذاتية حيث يعتمد التراتب القيمي دن أجل تحديد العلاقة بين الأنا والآخر. انطلاقا من هذا الأمر سعت مختلف الخطابات الفكرية إلى مراجعة ما هو سائد للكثف عن التحيزات الكامنة. اعتبارا مما سبق يتحدد الإشكال كالآتي: هل استطاعت المقاربات العربية أن تقدم حلا لإشكالية التحيز؟ هل تحررت من المرجعيات المستعارة كما أريد لها أن تكون؟

\section{مفهوم التحيز:}

يتأسس مفهوم التحيز على اعتبارين أساسيين: الاعتبار الأول تضخيم الذات والتمركز حولها ،إذ يتم التلاعب باللغة من أجل خلق تتمبطات جاهزة تسم الذات بكل سمات التعالي والفوقية ...وتجعلها رمزا للتحضر والكمال والعلم.....وهذا التمركز يعرفه عبد الله إبراهيم: "تمط من التفكير المترفع الذي ينغلق 
على الذات،ويحصر نفسه في منهج معينهينحبس فيه ولا يقارب الأشياء إلا عبر رؤيته ومقولاته،ويوظف كل المعطيات من أجل تأكيد صحة تلاك المقولات" .

الاعتبار الثاني تغييب الآخر أو انتقاصه وتهميثه في محاولة لإقصائه ،وذلك بوسمه بكل سمات

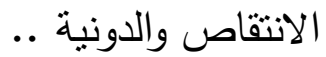

من هنا فاللغة تتحول إلى حقيقة ثانية لا تدل على أصلية الثنيء أو الظاهرة وإنما على متخيلاتتا أو متصوراتتا حولهاهواعتبارا من ذلك فالتحيز لا يستقيم إلا بعناصره أو مكوناته الثلاث:ذات مركزية ـ آخرية متخيلة . لغة تخييلية تعد وسيلة لبناء هذا التحيز. السياقات العامة للبحث في إثكالية التحيز:

تدخلت الكثير من الأحداث السياسية والاجتماعية والثقافية داخل الساحة العربية في توجيه الوعي

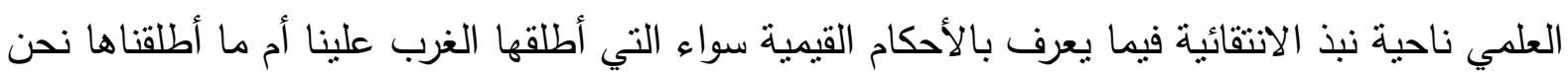
على الغرب ذاته،إذ الأيديولوجيا كثثرا ما تؤدي إلى تغييب الموضوعية ،وهذا ما سعت إلى كثفه مختلف الدقاربات المعاصرة .وانطلاقا مما قلناه سنسعى في هذا العنصر بحول الله إلى البحث عن السياقات العربية التي ظهرت في ظلها إنثكالية البحث عن تحيزات الخطاب.

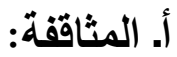

يتأسس مفهوم المثاقفة على الحوارية التي تتتفي معها حدود التحيز والإكراه، حيث يضفي إلى خلق حضور تتساوى فيه الأطراف، وإن ظل المصطلح رهين المثالية بسبب جاهزية الأحكام وسبقيتها واحتكار الحقائق عند البعض، مما يجعل للمفهوم التباساته المغايرة التي تحمل حكم قيمة تجعل من أمر تحققه مجزوء، حيث تختص به فئة محددة دون باقي الفئات، إذّما وراء المعنى هو الحقيقة، وحقيقة الحقيقة 
المضمرة، من خلال حب الذات وحب التملك يتم إخضاع الآخر لسلطة الذات. كل تاريخ البشرية يتجسد

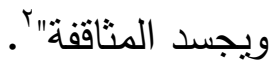

وقد ابتدع المصطلح من قبل الأنثروبولوجيين الأمريكيين في حدود عام .11 (،والمصطلح الذي كان يقابله عند الانجليز هو "التبادل الثقافي(exchange cultural)"،بينما عول الإسبان على مصطلح "التحول الثقافي (transculturation)،أما عند الفرنسيين فتم استخدام مفهوم "تداخل الحضارات (civilisation interpénétration) نشأت منذ عام ، 111 على يد بوي.J. W. powel والسابقة a في كلمة acculturation هي مشتقة من اللتينية ad التي تدل على حركة تتم على الاقتراب من.. ومع ذلك كان لا بد من انتظار الثلاثتينات من القرن العشرين لنشهد نهوض تقكير منهجي حول ظواهر تلاقي الثقافات"“موانطلاقا من هذا التاريخ لم يعد الأنثروبولوجيون الأمريكيون يقبلون أب تعريف غير دقيق، إذ قام مجلس البحث في العلوم الاجتماعية عام بسو ا في الولايات المتحدة الأمريكية بتكليف لجنة من أجل تتظيم البحث حول وقائع المثاقفة، وهذه اللجنة مكونة من روبيرت ربدفيلا ورالف لينتون وميلفيل هيرسكوفيتش، حيث أصدرت مذكرة لدراسة المثاقفة حوت توضيحا دلاليا، لتعتمد في الأخير التعربف التالي:"المثاقفة هي مجموع الظواهر الناتجة عن احتكاك مستمر ومباشر بين مجموعات أفراد تنتمي إلى ثقافات مختلفة تؤدي إلى تغييرات في الأنماط الثقافية الأولية للجماعة أو الجماعات"؛ إذن يذهب المصطلح إلى الدلالة على تلاقح الثقافات على اختلافها، من هنا فالمثاقفة تبنى على المشاركة العادلة، وهذه المشاركة نظرا لقيامها على مفهوم الاعتراف الذي يحمل أبعادا معرفية وأخرى قيمية أخلاقية، فإن النسبية تؤثز في هذا المفهوم وتحدد وجهته، مما يفسح المجال لاختلاف المعايير المناسبة والتي تختلف في مضامينها من طرف إلى آخر، وهذا ما يصعب من تحديد مفهوم المثاقفة الإيجابية والواعية، والتي تفترض انتفاء التفاوت وعدم احتكار الروية وإقصاء المنظور الأحادي الجانب، أو كما يسميه علي حرب "فخ الاستثاء وداء الاصطفاء"..، والذي يعني إلغاء التراتبية القيمية التي تظهر 
البشر في شكل ثنائيات متضادة يمنل طرفها الأول الخير المطلق والحقيقة الكلية الصادقة..، ويمنل طرفها الثاني الثر المطلق والحقيقة الجزئية أو اللاحقيقة إذا جاز لنا استعمال هذا المصطلح، ومن هذا المنطلق يمكن اعتبارها "احتواء لأنماط التفكير وتتميطها على وفق الأسس القاعدية للنموذج الجوهري وغير المعلن للمهيمن أو الغالب..".إذ يحل التتمبط الجاهز محل الحقيقة الموضوعية، لذلك كثثرا ما لـاهي يكون التفاعل احتفاء بقيم غيرية ومعايير أحادية الجانب، وتعديل لنسق الحياة ونمطها بما يساير هذا المنظور، فكثبرا ما تتدخل الرغبة لتعديل صيغة الإدراك وزحزحة تموضعاته الأصلية بما يجعل الذات تتهمك في النهل من الاعتبارات المغايرة التي تكون خارج حدود الهوية وارتساماتها، وبصفة عامة" تتتكل قيمة الناتج لعملية تداخل ونفاذ المجموعة من السمات ونماذج السلوك وأنماط التقكير حيث يمكن حصرها في القانون الفيزيائي على سبيل المماثلة المتعلق بمنطق القوة فهو من يحدد لنا الأثر الذي تحدثه طبيعة العنصر المتنقلة بالنظر إلى طبيعتها المختلفة الأداة والمكافئة على الحاجات ثانيا".

وللمثاققة أثثكال عديدة أهمها:

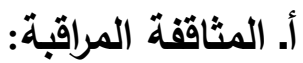

تتأسس المثاقفة في هذا النوع على المباشرة في ضرب الإثثات النقافية في نقاط ضعفها، حيث تحدث مقاومة في البداية سرعان ما تتراجع تحت داعي الانفتاح والتطور، لتتلاشى الكثير من القيم على إثر ذلك (كداعي الاستهلالك الغذائي واللباس..).

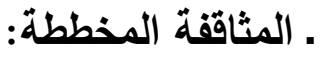

تتأسس على نية مبيتة مقصودة من أجل تحقيق أغراض محددة، فهي "مثاقفة مقصودة تكون موجهة

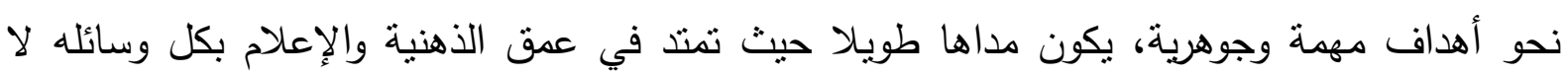
تخرج عن هذا السياق، معتمدة في ذلك على علم الاجتماع المعرفي أثناء نطوراته كغيره من العلوم 
الاجتماعية، من خلال تطور نظرياته، بحيث تعمل على القرب من الظاهرة، حيث يتطلب ذلك معرفة

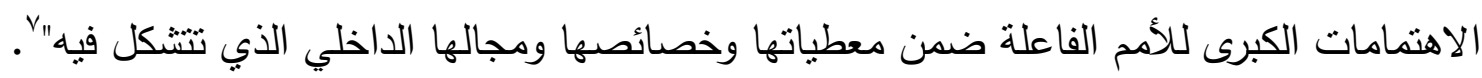

كما يمكن تقسيم أثنكالها إلى مثاقفة طوعية وأخرى قهرية، فالأولى هي التي تتحدد على وفق رغبة

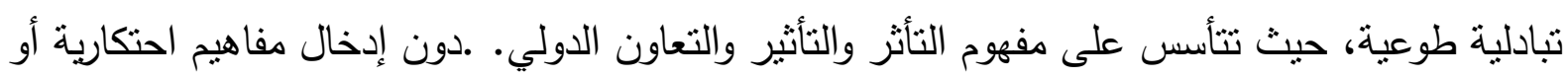
رؤية مركزية، وأما الثانية فتحمل مضامين إمبريالية ،لذلك تجاوز حدود التبادل والتعاون إلى الاختلاط لئل غير المنظم والذي يحدث نتوهات على مستوى الوعي ،نظرا لاعتماده على نظرة شمولية تقصي كل

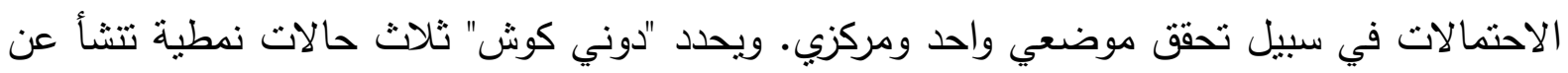
المثاقفة وهي: - n

"حالة مثاقفة "عفوية"، "طبيعية"، حرة" (ولا تكون الحالة كاملة أبداً في الواقع)وهذه المثاقفة لا تكون موجهة ولا مضبوطة". ويعود سبب التغير في هذه الحالة إلى مجرد الاحتكاك ويتم، بالنسبة لكل من الثقافتين المعنيتين، على وفق منطقها الاخلي الخاص بها. "حالة مثاقفة منظمة، لكنها قسرية وتتم لمصلحة جماعة وإحدة كما في العبودية والاستعمار. وهنا تكون الإرادة أداة تغيير لثقافة المجموعة الخاضعة على المدى القصير بهذف إخضاعها لمصالح المجموعة المسيطرة، وتبقى المثاققة جزئية، وفي أغلب الأحيان تتنهي إلى الفثل(من وجهة نظر المسيطرين)بسبب تجاهل الحتميات الثقافية.وغالباً ما يكون هناك انتزاع للثقافة بلاًا من المثاقفة. *حالة ثقافة مخططة ومضبوطة ترمي إلى أن تكون منتظمة تنظر إلى المدى البعيد. ويتم

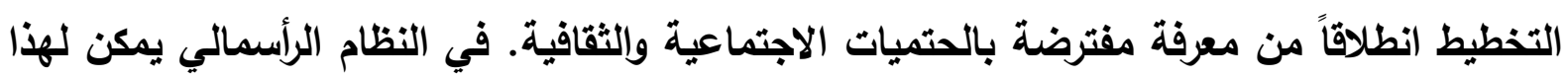
التخطيط أن يؤدي إلى" استعمار جليد ".و النظام الثيوعي يزعم بناء "ثقافة بروليتارية" تتجاوز

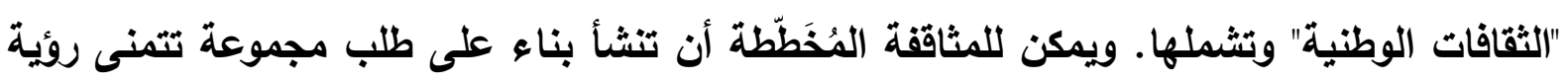
الاقتصادي تطورها

لتشجيع حياتها شكل تطوير 


\section{على سبيل المثال"ه.}

إن التتوع النقافي يفضي إلى تتوع الرؤى والأحكام والمعايير، مما يفترض إضعاف المركزية واحترام التعدد والاختلاف، ورفض تعميم القيم أو احتكار اصطناعها، والتبجح بأفضلية الذات في سياق البحث عن التبادل والتعاون هو إضعاف لفكرة الحوارية القائمة على احترام الاختلاف، وهذا الأمر سيجعل الذات تقاوم الآخر باستعمال صيخ خطابية متعالية نروج لفوقيتها ولنموذجيتها ،إذ "معروف أن صورة الآخر

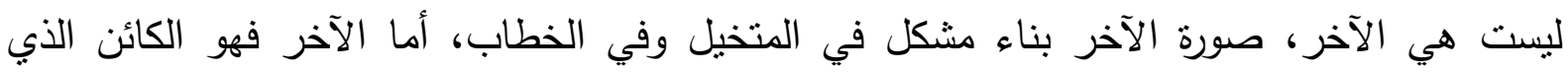
يتحرك في الواقع. والصورة ليست هي الواقع، غير أن الصراع حولها من رهانات الواقع. إن الصورة اختراع واختلاق وتلفيق وفبركة، والواقع ليس كذللك إلا حينما يتم تصويره وتمثلك وتمثيله وتخيله" هومن هن ثمة فهذه الصيخ المؤدلجة تحل محل النظرة الموضوعية التي ترى في الآخر وإنجازاته إضافة نوعية تتري المسار الأنوي وتساهم في ردم فجواته وسد ثغراته.

وربما ميكانيزمات المثاقفة التي اقترحها بيري berryهتوضح أكثر الاعتبارات الأيديولوجية، والتحيزات الكامنة في خطاباتها، سواء كان التعامل بمنطق الاعتراف بالغيرية المركزية مما يعني تذويب الحدود الأنوية وبناء مصطلح المثاقفة على آلية الطمس ،أم كان بمنطق التجاهل ،إذ رد الفعل كذلك ينطوي على أبعاد أيديولوجية متحيزة للذات، وهذه الميكانيزمات هي:

"الإستيعابassimilation :ويقصد به أن الفرد يترك هويته التقافية الذاتية لأخذ هوية ثقافية مهيمنة. التهميش marginalisation:وفيه ينرك هويته الثقافية دون الأخذ أو رفض الثقافة المهيمنة. الانفصال Séparation:حيث في هذه الحالة، يأخذ الفرد هويته الثقافية دون الأخذ بالثقافة المهيمنة. الاندماج intégration :في هذه الحالة بأخذ الفرد هويته الثقافية وكذلك بأخذ بالثقافة المهيمنة"'. 
إن المنفعة والحقيقة هي ما ثقوض إمكانية المثاقفة السوية، والتي تتحدد تموضعاتها المفاهيمية في إطار محتمل يتوخى التفاعل الحر والاختلاف والمساواة في الفرص والحوار المنبادل ،ومن ثمة يكون التقاعل واعيا بحدود الهوية التقافية ،لذلك فالمثاقفة التي لا يبرأ خطابها من إكراهات الآخر وحدود رؤيته وتحيزاته الكامنة في مضمرات خطابية محددة هي ما تحددت بشكل مركزي على إثر اعتلا العلاقة بين الذات والآخر ، وحضور مفاهيم التبعية والتقليد والمحاكاة بدافع الكونية، ولربما تحوله إلى حكم قيمة مسيج بالإيجاب هو ما يغفل جانبه التحيزي، الذي يجعله يظهر بموازاة الاحتكار التقافي، إذ يظهر في انسجامه كلا متكاملا ولا يقر بباقي الأجزاء أو التشكيلات المغايرة، وهذه النظرة هي التي تكافح المثاقفة السوية من أجل تقويضها ،حيث تسعى إلى تحرير الآخر من منظوره التمركزي الأيديولوجي وتعميق الإحساس بضرورة الاختلاف والتتوع والاعتراف.

ب ـ تأزم الذات ـ نحو الخواء الأيديولوجي وإشكالات الهوية بعد نكسة يونيو IV .

بعد نكسة حزيران VT وخيبة المشروع القومي العربي في تحقيق أهدافه، أصيب الإنسان العربي بتأزم على مستوى الوعي،مما حتم عليه مراجعة الكثير من المفاهيم التي تتعلق بالهوية والوجود وصيرورة المجتمع العربي واعتبارات الوحدة ومآل الصراع العربي/الإسرائيلي، وهذا الأمر جعل جميع الخطابات القبلية محل نقد ومساءلة، استجلاء لعلاقة الأنا بالآخر، وعلاقة الأنا بالتاريخ وبالهوية والمجتمع، فقد بدأت على إثر ذلك مرحلة جديدة من الخضوع إلى النظام الرأسمالي العالمي، ورافق هذا الأمر تفاقم عنصرية الدولة الصهيونية، مما ساهم في خلق جو من الإحباط والقلق داخل الثعوب العربية، خاصة مع التفكك الاجتماعي والطائفي وانتشار الفقر والبطالة واستفحال الصراعات والانقسامات.

إذن وقع تباين في الآراء بعد الهزيمة في محاولة للبحث عن الأسباب الرئيسة ،فكان فكر هذه المرحلة يخلق أسئلته اعتبارا من موضعية الذات ومرتكزات الهوية، حتى وسم هذا الفكر بكونه فكر الهزيمة، إذ المحاولات لم تجاوز حد البحث عن مخارج لهذا المأزق، وقد شكل كتاب "صادق جاص 
العظم" والموسوم ب"النقد الذاتي بعد الهزيمة" انطلاقة نحو قراءة الذات والنقد الأنوي،حيث جمع بين

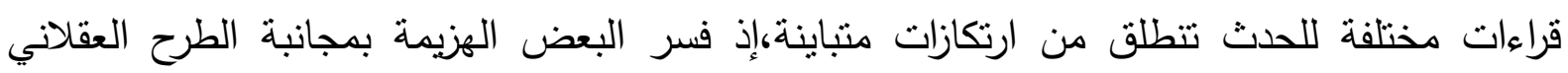
والمشروع العلماني والأخذ بالخطاب السلفي،الذي لم يجاوز راهنية اللحظة التاريخية باستدعاء اعتباراتها واستحضار رموزها .يقول في نقده لمصطلح النكبة:"إن مجرد استخدامنا لمصطلح النكبة في الإشارة إلى حرب حزيران ونتائجها ينطوي على الكثبر من منطق التبرير والتهرب من المسؤوليات والتبعات،لأن من تحل به النكبات لا يعد مسؤولا عنها وعن وقوعهاهوإن كان كذللك فإن مسؤوليته تعد جزئية جدا بالقياس إلى هول النكبة وعظمها. لذلك درجنا على نسبة النكبات إلى الدهر والزمان والطبيعة، أب إلى عوامل لا سبطرة لنا عليها ولا يمكن أن نحاسب على مجاري أحداثها" ".إذن اعتبارا من هذا الحدث ظهرت دعوات مختلفة إلى نقد العقل العبي ونقد الأيديولوجيا العربية التي حملت مضمرات خطابية تحيزية منغلقة وانتقائية، كانت السبب في تقوقع الفكر العربي وجموده وانتقائيته.

من هذا المنطلق تباينت الآراء حول مسألة الهوية إلى درجة التتاقض بسبب التجزئة القطرية والطائفية والطبقية والإثثبة والعشائرية، فبين تبارات احتقت باعتبارات الحاضر وأخرى استعارت اعتبارات الماضي، ظهر الاختلاف المفاهيمي حول تحديد المصطلح إن الهوية وعي الذات باعتباراتها وخصائصها النوعية الني تتحدد وفقا للحظة زمنية سابقة وأخرى متحققة أو في طور التحقق ترتسم حدودها ضمن إطار المصلحة المشتركة، أو هي السمات والخصائص التي تميز جماعة إنسانية محددة عن باقي الجماعات، حيث تظهر في صورة مفاهيم عقائية ونفسية وفكرية وتاريخية تموضع الفكر في إطار ينغلق على اعتباراته ويمنع كل التمايزات الداخلة، والتي تهدف إلى التثويش أو التتنتي، أو يمكن اعتبارها تفاعل جملة اعتبارات كاللغة والتاريخ والأيديولوجيا والدين....من هنا فهي "مركب من المعايير، الذي يسمح بتعريف موضوع أو شعور داخلي ما. وينطوي 
الثعور بالهوية على مجموعة من المشاعر المختلفة، كالثعور بالوحدة، والتكامل، والانتماء، والقيمة، والاستقلال، والثعور بالتقة المبني على أساس من إرادة الوجود"' .

يظهر الحديث عن الهويات حينما تكون مهددة بالزوال ،ولا يكون الأمر كذلك إلا حينما تواجه الذات بمأزق الانتقاص والتهميش، حيث تتموضع داخل إطار أقل ما يمكن أن يوصف به أنه مهتز المكانة بسبب وسمها بالأقلية، والأقلية هنا تتجه نحو تحديد مفهومي مغاير عما درج عليه سابقا، فبعد أن كانت تتبع الكم صارت تعني درجة أقل من التأثير والغلبة داخل المجتمع الدولي، لذلك وتطبيقا على راهنية الحدث ـ أي النكسة ـ في آثارها على المجتمع العربي، فقد تزايد الوعي بالهوية واعتباراتها بعد نراجع الخطاب القومي والذي وعد بإيجاد صيخة وجود مركزية للذات العربية ،أو بخلق زمن عربي بعيدا عن كل التشويشات المغايرة، حيث أن الفشل أعاد سؤال العلاقة الجوهرية بين الأنا والآخر.

\section{ج. ـ العنف والإرهاب:}

ظهر مصطلح "الإرهاب" في أوائل السبعينات من القرن الماضي، حيث دل معناه على العنف المرتكب إزاء فرد أو جماعة، وقد شاع استخدامه في العالم مع ازدياد نسبة الجريمة ،هذا ما دفع العديد من العلوم تهنم بالبحث عن التباسات المفهوم ودوافعه، كعلم النفس، وعلم الإجرام، وعلم الاجتماع....إذ الظاهرة تم معاينتها باعتبارها حالة اجتماعية وسياسية في الوقت ذاته" والواقع أن الإرهاب المعاصر أصبح نشاطا بالغ الخطورة والتعقيد بحيث أصبحت تديره منظمات على قدر عال من الخبرة والتظيم والتدريب والتسليح والخبرة النفسية لذا تجد أن كثيرا من المنظمات الإرهابية تديرها المخابرات المركزية لبعض الدول، في سبيل بسط نفوذ تلك الدول وفرض سياستها وترهيب كل من يحاول أن يزيغ عن نهجها" أوتباينت الآراء حول تعريف المصطلح بسبب دخوله ضمن المصطلحات الحديثة والمبتكرة، حيث صار يوسم به جمع من الناس يسلكون سبيل العنف من أجل تحقيق غايات سياسية. 
والإرهاب مأخوذ من كلمة (terror) في الانجليزية، والتي تعني الخوف والفزع، ومنها اثتق مصطلح(terrorism) والذي يدل معناه على استخدام وسائل استثنائية توسم بالعنف الجسدي أو المعنوي من أجل تحقيق غاية ما، أو يمكن اعتباره جملة اعتداءات فردية أو جماعية ينفذها فرد أو جماعة بغية التأثثر على من حولهم ،وتؤدي إلى حالة من انعدام الأمن ،"فأن تدعى إرهابيا، يعني أنك متهح بأن دماغك قد غسل، وأنك تتبنى بالمقابل مذهبا مفخما مستوحى من فعل القتل الصرف" اء'. ويقدم الباحث "نعوم تتومسكي" تعريفا للإرهاب حيث يقول: "نستخدم تعبير الإرهاب للإنشارة إلى التهديدات باستخدام

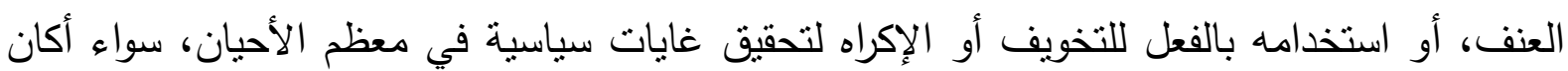
إرهاب الجملة الذي يمارسه الأباطرة، أم إرهاب التجزئة الذي يمارسه اللصوص" أ.ولربما تعريف الباحث عبد السلام بن عبد العالي يقدم منظورا مغايرا بنفي الغاية التي توجه الفعل وتؤطره، حيث يظهر عنده

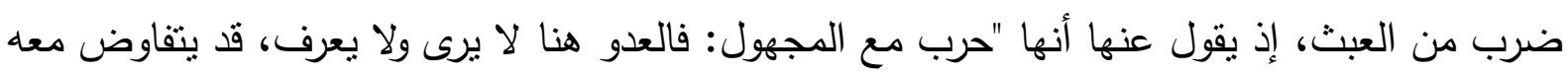
وقد يحاور، إلا أنه يظل مجهولا، وهي حرب لا تنتهدف إلا ذاتها: فغالبا ما تتتهي العمليات التي تتطوي عليها دون تحقيق مطالب ولا وصول إلى غاية"'ال.

ونحن نجد أن التعريف الأول أقرب إلى الموضوعية وإلى توصيف الظاهرة، لأن تغييب الغاية لا

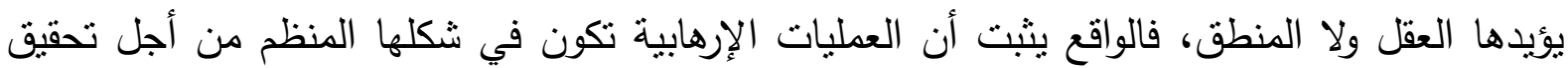
مآرب محددة ومن بينها ضرب المركزيات المنتشرة والرد على عنفها بعنف أكبر والتعبير عن حالة غضب أو صيغة اعتراض على الوضع القائم، بغض النظر عن الوسيلة المستعملة. ولو أن "فؤاد زكريا"

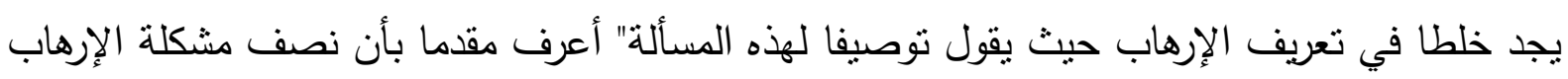
على الأقل، يكمن في الاستخدام الفضفاض ،المتعدد المعاني لهذا اللفظ، وأعترف بأن هذا التعدد والخلط ليس مجرد مشكلة لغوية، وإنما يعكس وجهات نظر منضادة إزاء قضايا الثعوب، ومشكلات التحرر، وعلاقات القوة في العالم المعاصر، وربما كان يعبر في نهاية المطاف، عن موقف أساسي من قضية

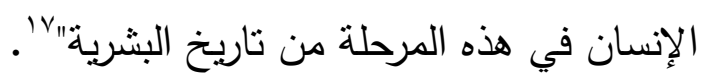


والمشكل ذاته يقر به الدكتور محمد سبيلا حيث يقول: "مشكل تعريف الإرهاب. ليس مشكلا إبستمولوجيا بقدر ما هو مشكل سياسي، ذلك أن هنالك حدودا رفيعة وحساسة بين العنف السياسي المشروع. .وبين العنف السياسي غير المشروع الذي يدخل في خانة الإرهاب، فإذا كان بالإمكان تعريف الإرهاب بأنه

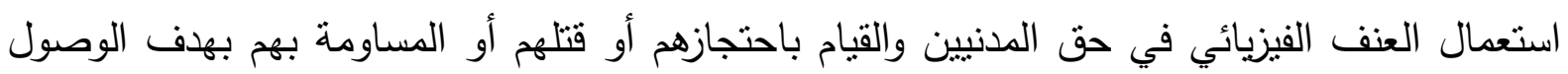
إلى تحقيق أهداف سياسية، فإن سمته الأساسية دمويته وشراسته ونزعته الانتقامية التي تطال أطرافا أو فئات مدنية لا علاقة سبيية مباشرة لها بالأسباب التي يمكن للمقترف الاستتاد إليها دون مراعاة للنتائج

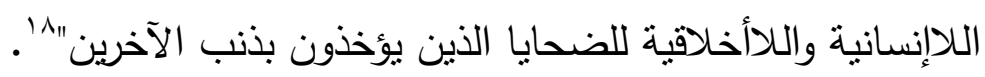

وأما "بنيامين ننتياهو" فيعرف الإرهاب كما يأتي :"الإرهاب هو استخدام العنف الإرهابي ضد دولة معينة بواسطة دولة أخرى تستغل الإرهابيين لشن حرب من خلال الأفراد كبديل للحرب التقليدية، وأحيانا يأتي الإرهاب من حركة أجنبية تتمتع بتأييد دولة مستقلة تسمح ونتجع نمو هذه الحركة على التى أراضيها"19.وما نلاحظه من هذا التعريف هو ذللك التعميم المضلل ،والذي يستهدف وضع المقاومة المشروعة . كالمقاومة الفلسطينية . في موضع اتهام وشبهة من أجل تصفيتها وتأليب الرأي العام عليها. لذلك فجون بودريار يقدم تقسيرا لهذه الظاهرة باعتبارها رد فعل طبيعي لعنف مقابل، إذ يقول :"إن النسق هنق هو ذاته الذي خلق الثروط الموضوعية لهذا الرد العنيف. فباحتكاره لجميع الامتيازات ،يرغم الآخر على بهى بهري تغيير قواعد اللعبة .والقواعد الجديدة متوحشة ،لأن الرهان ذاته متوحش. فاتجاه نسق يجعل اكتساب القوة تحديا قاهرا يرد الإرهابيون بعمل حاسم بحيث لا يمكن كنللك بالدقابل أن يرد عليه.إن الإرهاب هو العقل

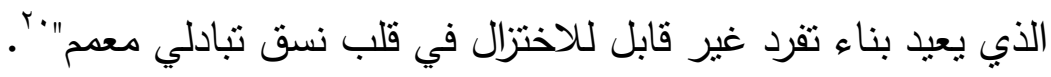

وأما العنف فهو "كل سلوك . فعلي أو قولي . يتضمن استخداما للقوة أو تهديدا باستخدامها لإحاق الأذى والضرر بالذات أو الآخرين، وإتلاف الممتلكات لتحقيق أهداف معينة" ".أو يمكن اعتباره "إيذاء أو له تدمير الجسد أو العلاقة يقوم به شخص تجاه آخر أو جماعة تجاه أخرى"r"،ويكمن الفرق بين الإرهاب 
والعنف في كون الأخير وسيلة من وسائل الإرهاب بل أحد ركائزه، إذ" أب سلوك شخصي ومؤسساتي يتسم بطابع تدميري مادي واضح ضد آخر يعد عملا عنيفا .هنالك العنف الثخصي الخفي، الذي يؤذي الآخر نفسيا، وهناك العنف المؤسساتي الخفي ،حيث تتنكل البنى الاجتماعية هوية مجموعات

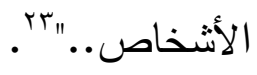

منذ 1) أيلول/سبتمبر | . . وظف مصطلح "الإرهاب" توظيفا إمبرياليا، حيث هدف إلى حشد القوى العالمية لمواجهة الإرهاب الدولي، مستغلين شعارات أيديولوجية تضمر تحيزات واضحة وتضليلا عن عدوانية مبيتة أو رغبة استيطانية، إذ نم استدعاء بعض المصطلحات من الذاكرة التاريخية تدل اعتباراتها على هذا التهويم الأيديولوجي من قبيل "الحرب الصليبية الدقدة ـ حرب العدالة المطلقة . حرب

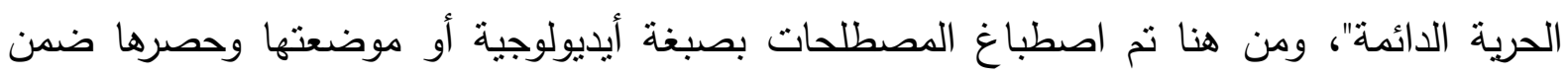
رؤية غيرية تعتمد معايير الغرب كحكم قيمة مطلق، وتم في هذه الرؤية التركيز على الموضعية الاتهامية للمغاير بهدف تصفيته وإزاحة مركزيته وزعزعة نظامه، ليتم إعادة الجدل الدائر حول صدام الحضارات . ويحاول إدوارد سعيد أن يجد تفسيرا للحادثة بقوله:" أعتقد أن الحادثة قد جاءت في أعقاب جدل طويل حيال تورط الولايات المتحدة في الخارج والذي امتد عبر القرن الماضي برمته. وشمل ذلك التنخل في شؤون العالم الإسلامي والدول المنتجة للبترول والعالم العربي والثرق الأوسط، كل تلك المناطق التي لتي يجري النظر إليها بوصفها أساسية لصياغة المصالح والأمن الأمريكيين، تلك المصالح التي تضم البترول والقوة الإستراتيجية معا، إضافة إلى إيجاد موطئ قدم للولايات المتحدة في الخليج الفارسي والسيطرة عليه وحماية حلفاء الولايات المتحدة من أمثال إسرائيل والعربية السعودية وآخرين. وخلال كل هذا الجدل الذي واكبته سلسلة من التذخلات المستمرة، لعبث الولايات المتحدة دورا بارزا بالنسبة لسكان تلك المنطقة، وهو

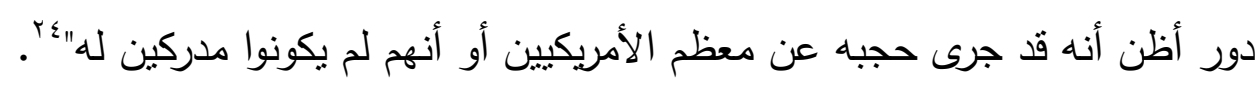


إذن تظهر الدوافع واضحة ،في محاولة للتغيير في الجغرافية السياسية أو الطبيعية وفي المصالح والعلاقات الاجتماعية والدولية بطريقة قاسية، أو فرض هيمنة ومصالح وأيديولوجيات وعقائد وأفكار وتقافات محددة عن طريق الإرهاب المكثف، وعلى هذا الأساس أعطت الدول الغربية مصطلح الإرهاب أبعادا ذاتية تحيد به عن معناه الأصلي،إذ جعلته مصطلحا خاصا بجماعات تحاول البحث عن موضعية خاصة في إطار معولم أرغم العالم أن يكون ضمن صورة موحدة من خلال تلاشي الهويات، لذلك سعت إلى فرض معايير إنسانية وأخلاقية ودولية من أجل إيجاد صيغة موحدة تخدم منظورها الخاص .ومن هنا فالمصطلح وظف سياسيا ،إذ تم معه وسم بعض الجماعات التي تحاول دفع العدوان ـ كما في حالة الدول المستعمرة . بالإرهابيين لتتحول القضية إلى معارضة للمصالح تحتم في الأخير تصفية تامة، واعتبارا من هذه الرؤية نجد أن المقاييس الأخلاقية "التي يصدر العالم على أساسها حكمه بأن هذا الفعل العنيف مشروع أو غير مشروع ،أخلاقي أو غير أخلاقي، هي مقاييس مشوهة ومضللة أو متحيزة إلى حد بعيد" "لهذا ودفعا لهذه الرؤية المتحيزة يرى عبد السلام بن عبد العالي أنه ينبغي" ألا نخلط بين الإرهاب وبين كل أثكال المقاومة التي عرفها التاريخ المعاصر، ولاسيما النضال الذي ميز حركات التحرر ضد الاستعمار السياسي. فإضافة إلى أن نلك النضالات تقوم على روية إلى التاربخ وإلى الإنسان تبرر الأفعال وتعطيها معانيها، فإن الإرهاب يرتبط بصفة جوهرية بما استجد في حياتتا المعاصرة وعلى

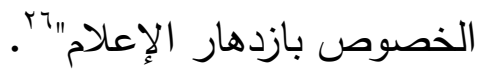

وتتعدد دوافع العنف "إذ يجسد غريزة العدوان أو منطق التفاضل أو إرادة التسلط أو عقلية الإقصاء والاستئصال" "وهومن هنا فالعماء الأيديولوجي والتطهير العرقي الذي تحركه اعتبارات مركزبة يزيد انتشاره كلما تراجعت مفاهيم الحوار والاختلاف والمشاركة الفعالة، وكلما سعت الذات إلى تضخيم اعتباراتها بدافع المقاومة ،لذا تتتج خطابات عدائية وتعتمد في ذلك صياغة فوقية متعالية لا تذل على حقيقة الذات بقدر ما تعكس نمط التفكير المتحيز، والذي يرى في كل اختلاف اعتبارا خاطئا لابد من زعزعة نظامه والقضاء عليه، إن العنف وسيلة الخطابات الوثوقية المنغلقة ،لكن"لا يكون الفكر الوثوقي الدوغمائي إذن 
عنيفا بما يترتب عليه من أعمال وما يصدر عنه من أقول، وإنما بما هو ينثد، أو لنقل بما هو ينشد إلى ما يعتقد أنه طبيعي مسلم به.العنف هنا عنف بنيوي.إنه مبدأ وليس نتيجة، إنه نسيج الفكر الدوغمائي. وهو غالبا ما ينقوى ويتضاعف حينما ترتبط الوثوقية أيضا بالتشنج واحتكار الحقيقة وقمع الآراء المخالفة"^^، ولو أن الباحث رجب أبودبوس يجد أن" الذين يلجؤون إلى القمع البوليسي والإرهاب الفكري إنما يفعلون ذللك لأنه يعوزهم المنطق والوثائق والحجة العلمية فيحولون المواجهة من مستواها الفكري

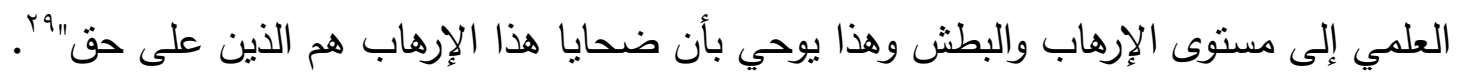
دـ العولمة:

اعتبر بعض الدارسين أن مفهوم العولمة طرح في أواخر الستينيات أو السبعينيات على يد كتاب أمريكيين اهتموا بالثأن السياسي، وظهر بالتحديد في كتاب"ماك لوهان وكينتين فيور" الذي يحمل عنوان "الحرب والسلام في القرية الكونية"، إضافة إلى كتاب "بريجنسكي" الموسوم ب"بين عصرين :دور أمريكا

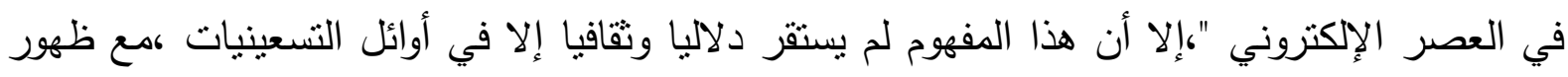
ثورة التكنولوجيا والإعلام والاتصال... وما تبع ذلك من تطورات على مستوى التجارة الدولية والاقتصاد العالمي، وظهور ليبيرالية جديدة متتشدة بعد تفكلى الاتحاد السوفياتي .والعولمة مرادفة

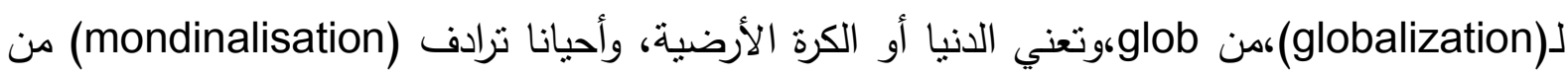
monde

وعرفها الدكتور "رجب بودبوس" بقوله "العولمة باختصار هي صيرورة العالم سوقا ماليا وسلعيا

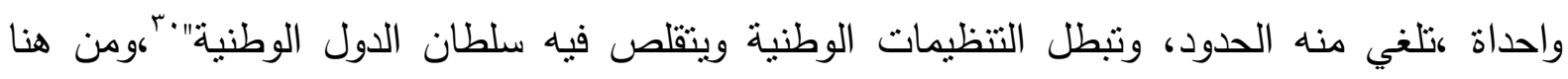
فالمصطلح يختزل كل المعطيات والاختلافات والتتويعات المعاصرة، ويحاول تغطية مضمرات منها الهيمنة الأحادية لنظام الليبرالية المتطرفة ،والذي يتمتع بقوة عالمية ،إذ يصبح خيارا سياسيا وحيدا معبرا عن أيديولوجيا اصطفائية تلغي الآخر واختلافاته . 
وعلى الرغم من أن المصطلح يهدف إلى تحديد حالة العالم، فإنه يمارس تعتيما وذللك بالاعتماد على مصطلح غامض اختزالي ،ليس له معنى حقيقي أو معنى محدد، لذلك تشكل العولمة" جزء من هذه اللغة لنة المكونة من مصطلحات، والتي محرفة لأغراض دعائية فعالة ،لها موهبة الإقناع دون برهان ،مجرد الإثارة إليها تتيح تلاعبا عظيما بالعقول ،والتي حالما يجري إدخالها في اللغة الاعتبادية ،لدرجة أنها تستخدم حتى من قبل الذين يعارضونها ،فإن هذا يجعلها تندو واضحة ويقينية ،وبالتالي تتجز ما كانت

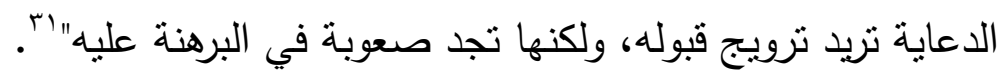
وتتجه العولمة نحو تتميط العالم ـ بمستوياته المختلفة ،حيث الاعتماد على جاهزية الخصائص والقيم تحت مسمى الاشتراك والانفتاح ،لذلك فهي تهدف إلى إلغاء الحدود والفواصل، وهو ما يجعلها ذات منحى تطرفي مركزية لأنها تلغي جميع الاعتبارات المغايرة من أجل نمذجة واحدة أو معيارية مصطنعة من قبل المركز الغربي ،إذ تتفى كل الاحتمالات ليستحضر مفهوم الهيمنة الأحادية ،وذللك ما يجعل العولمة رديفة لمصطلح "الأمركة "،حيث يصبح العالم في منظورها "وحدة عضوية منكاملة، وليس قارات متباينة، أو أنظمة اقتصادية وسياسية متفاوتة، بل هو كيان واحد لكنه ليس كيانا ميتافيزيقيا أو كائنا روحانيا، وإنما هو سوق كونية كبيرة مسكونة بمستهلكين فعليين أو افتراضيين. إن العالم ،في هذا

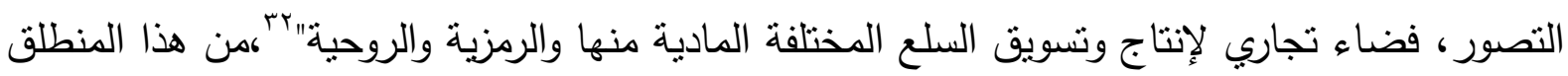
يمكن القول عنها أنها تتثبع" وتتخذى من العجرفة التقافية التي تمتح أصلها من الجهل واللامبالاة تجاه أنساق قيم أخرى وتجاه حقها في الوجود. ويؤدي هذا بشكل تدريجي وفعلي إلى نزعة ثقافية تنلطبة

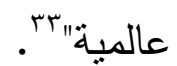

وقد وضح سعد البازعي التحيز الأيديولوجي للأات الغربية في خطاب العولمة ،حيث قال :"إن ما يشار إليه الآن بالعولمة ليس جديدا كل الجدة، بل إن الظاهرة كغيرها، نطور لمراحل سبقتها ،بل هي كما لاحظ العديد من الباحثن، امتداداً لتلك الظاهرة المألوفة، ظاهرة الاستعمار الغربي الذي عرفه العالم منذ 
قرون. .إنها ببساطة هيمنة الغالب، وليس أمام المغلوب إلا أن يعي موقعه، وأن يسعى للتعامل بواقعية

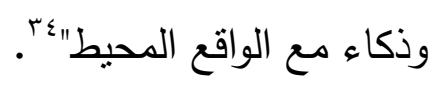

إن العولمة تمارس سياسة الطمس والاستبعاد للتشكيلات الثقافية الأصيلة، وتساعد على ظهور الفكر الامتثالي للآخر ، وذللك بتحويل كل المغايرات إلى عناصر هامثية.

إذن تتحدد صيغة العداء للاختلاف حينما يظهر النزوع إلى مركزية الذات وهامشية الأطراف الأخرى ،حيث تسعى الذات الغربية إلى فرض قيمها ومعاييرها واعتباراتها وتعديم نموذجها على العالم ككل دونما

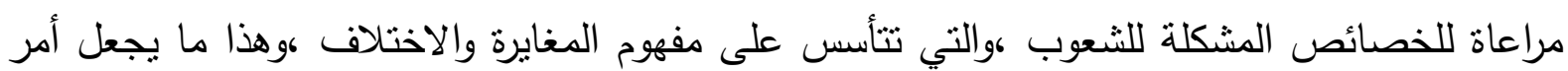
التنخل مبررا من وجهة نظر غربية صرفة، حيث يتم اعتبار كل القيم المغايرة حاملة لكفاهيم الإرهاب ومنتهكة لحقوق الإنسان، وهذا ما يؤصل للنرجسية الفكرية ولعنصرية التفكير ."إن العنصريين نرجسيون ينغلقون على نظرتهم الخاصة عن العالم ويتكرون لنظرة الآخرين لهم والواقعية، ولعالم الآخرين ،تعكس سلوكهم منظومة ضيقة ومنحرفة من المفاهيم والدلالات عن الدم والعرق،وعن الأخلاق ،والذهنيات ،والعلم

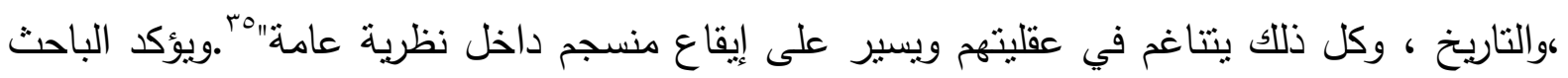
المغربي المهدي المنجرة هذا النزوع نحو النطرف في خطاب العولمة ،إذ يقول :"إن العولمة ،كما هي

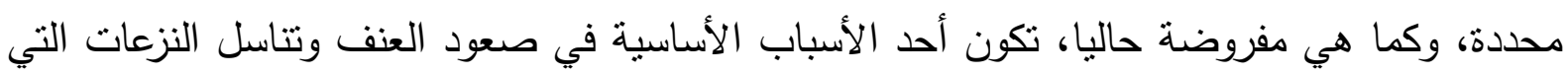
نلاحظها على المستوى الكوني .العولمة هي أيضا ذلك العقل المناسب لمواجهات كونية أخرى ،أكثر حدة

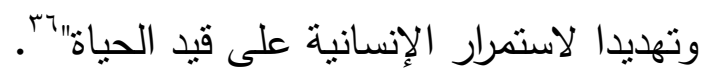

يبدأ العالم انطلاقا من ذلك في التجرد من الأثكال القديمة ليتجه نحو كونية جديدة، وتتم الصياغة بسرعة كبيرة ودون مراجعة ذاتية، حيث يستلب الوعي ويوجه في خدمة القوى المهيمنة ،و ما يمكن استتناجه أنها "ذات طابع يقوم على التوسع والسيطرة، فما أن قامت حركات التحرر في العالم بالاعتقاد بأنها تخلصت من نير الاستعمار الحديث حتى وقعت تحت استعمار آخر وبنمط جديد. وهو النظام 
العقلي الجديد. وهو يقوم على تسخير الشعوب ولو بالقوة للسير على حمل أرزاقها لترميها داخل الخزانة الأمريكية" "كومن هنا فالعولمة تتجه نحو تمثيل عالم تغيب فيه الحدود الطبيعية الجغرافية والاجتماعية والسياسية، وتتنفي فيه الانتماءات والولاءات، لتصبح "على المستوى الاقتصادي والاتصال وحيدة الاتجاه تسير من الغرب إلى الثرق أو من الثمال إلى الجنوب وليس العكس .أي أنها تسير من الدول المسيطرة

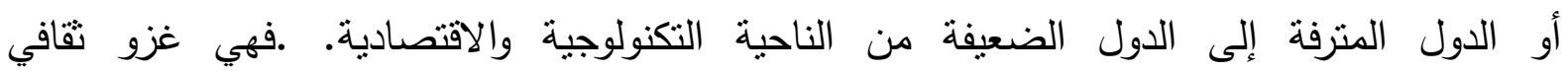
متكامل"، "حيث يفرض المثال الأمريكي نفسه ليدمر كل المنظومات الاقتصادية المغايرة.

وتعتمد العولمة في ذلك آليات مختلفة تتأسس على منطق الأحادية سواء على مستوى الاختراق أم

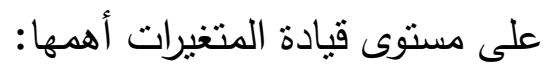

ـ انصهار الثقافات المحلية وتراجعها فاسحة المجال أمام الثقافة العالمية لتتذذ موضعية مركزية. ـ ظهور الانقسامات الثقافية والحضارية، وعجز الثقافة الوطنية عن تقيم بدائل مستقبلية. • ظهور روابط تضطلع بمهة البحث عن المعايير والقيم الملائمة والتي تكون سبيا في تقبل النقافة

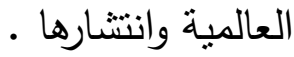

هذه الآليات تساهم في خلق ما يمكن اعتباره إرهابا فكريا ،إذ يقدم الإعلام صورة لآلة التنمير الغربية في شكل محبط ،حينما يموضعها في إطار متعال وذللك بتمثيلها خطابيا وفي صيغة استعراض على شكل قوة لا تقهر، في حين يمنل الثعوب الأخرى تمثيلا دونيا يهدف إلى إثعارهم بالهزيمة قبل وقوعها، لنظهر أمريكا في الأخير والعالم الغربي في صورة قدوة أو الرجل المخلص، الذي سيخلص الناس من

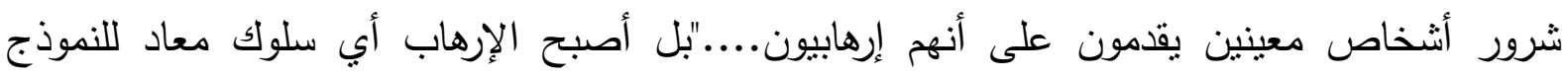

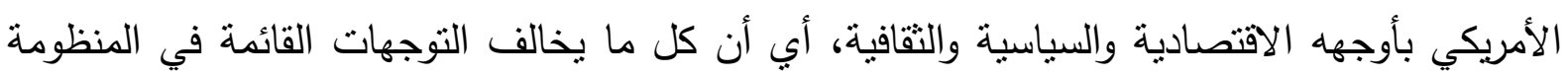
الجديدة يعد شكلا من أثنكال الإرهاب، وقد أدى هذا إلى حشر كثير من الفئات المذكورة في أماكن 
معزولة، بحيث تم نفيهح من البشرية كما يحدث في أماكن مختلفة من الأرض، في آسيا وأوربا وإفريقيا، وربما في أمريكا اللاتينية..." م9".

والسؤال الذي بطرح نفسه: كيف يتم التعامل مع العولمة ومع تحيزاتها الكامنة والمضمرة؟.

يجيب سعد البازعي عن هذا الإثكال باقتراح حل وسطي هو ما يسميه "التعامل الجاد" مع العولمة، إذ يشترط شرطين لتحققه أولهما: "التخلص من الآمال المثالية أو الطوباوية في الاحتفاظ بهويات نقية أو هو أوضاع ثقافية واجتماعية شديدة الخصوصية وخالية من مؤثرات الآخر الغربي، سواء كانت مؤثرات بناءة

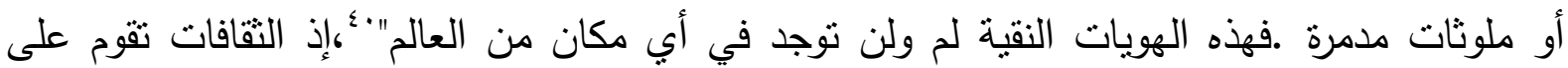
مفهوم التجاور والمشاركة والتبادل الاجتماعي والتجاري والسياسي، وعلى إثر ذللك يهيمن طرف من

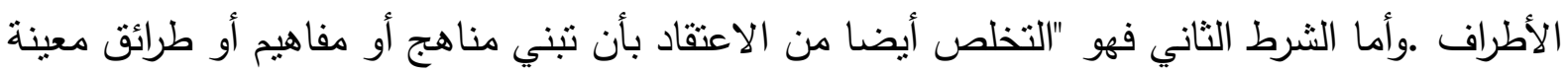

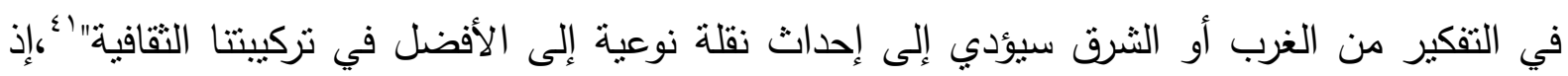
الفلسفات والمناهج وغيرها ليست بالحلول السحرية كيتم استدعاؤها وتطبيقها في مجتمع يفتق لذات الثروط الثقافية للمجتمع المغاير الذي استعيرت منه هذه الفلسفات والمناهج، فكل مجتمع يحتفظ بخصوصيته الثقافية واعتباراته الاجتماعية والسياسية والاقتصادية، والتي تضبط عملية الثأثر والثأثير . وربما قريب من هذا المعنى ما عبر عنه المفكر اللبناني "علي حرب" في قوله :"لا أعنبر العولمة مجرد إمبريالية معاصرة أو ليبيرالية جديدة أو هيمنة أمريكية ،كما لا أرى إليها كتأليه للسوق أو كتسليع للثقافة والعقول والأجساد، كما برى إليها الكثيرون من المنققين الدذعورين من عصر المعلومة والصورة والثبكة .فذللك تبسيط وتهويل وتهويم يجعلنا نتعامى عما يحدث ويتثكل على أرض الواقع المعاش .الأحرى التعامل مع العولمة كمفردة وظاهرة، بصفتها ثمرة الطفرات والانفجارات والتحولات المتسارعة. والكاسحة التي تضع المجتمعات البشرية أمام التحديات الجسيمة والخطيرة ،فإن لم تحسن التعامل معها

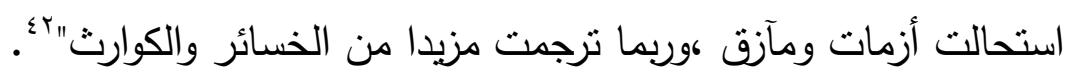




\section{(المقاريات العربية التي بحثت في إثكالية التحيز:}

سعيا منا لتوضيح الإثكال أكثر ارتأينا اختيار نماذج توضيحية لأسماء نقدية بحثت في مضمرات الخطاب وتحيزاته الأيديولوجية، واكتقينا هنا بأربع شخصيات متلت انعطافة نحو الاهتمام بما يخفيه كل خطاب من رؤية للأات والآخر ومتصور العلاقة بينهما ،وهي :أنور عبد الملك ـ إدوارد سعيد . حسن حنفي • عبد الله إبراهيم.

أ. أنور عبد الملك والبحث عن الخصوصية:

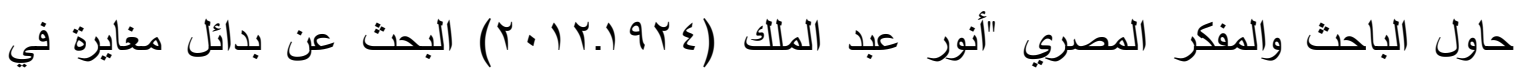
مواجهة التأثير الغربي، حيث سعى إلى الكثف عن النية المبيتة في خطاب الاستشراق ،والذي يسعى إلى بـ

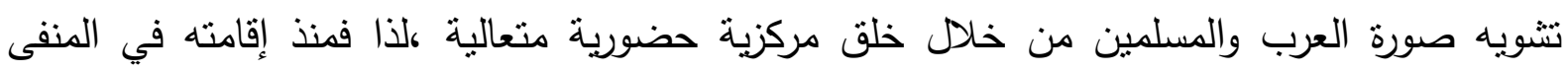
الاضطراري بفرنسا عام 909 (،وانضمامه إلى المركز الوطني للبحث العلمي في باريس، تأكد أن نظرة

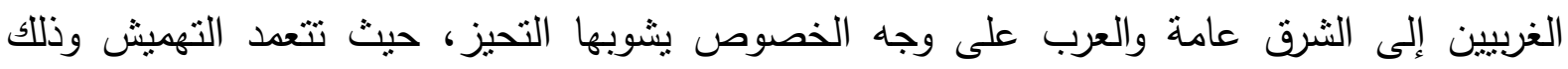
باعتباره مكونا استثنائيا لا يرتقي إلى أن يكون حضورا فاعلا. هذه النظرة جعلته ينشر مقالا بالفرنسية في مجلة "ديوغينيس diogenes"عام 197 موسوما

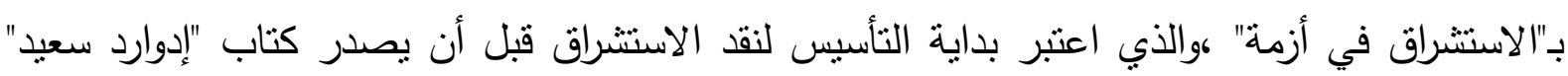
عام 19V1.

ويوضح الباحث هذه النظرة التحيزية في كتابه "تغيير العالم" حيث يقول :"إن العالم كان ولايزال وسيظل، نظرة دائرية تمثل أيضا نظرة مراكز الهيمنة التقليدية، وقد عرفت كيف تحاصر نتائج الاكتثافات الحديثة الخاصة بالحضارات والثقافات الأخرى وتضعها في إطار سلفي منمق باسم" الاستشراق" فلا وجود للثرق الحضاري الثنامخ وحضاراته العريقة ،واستمرار خصوصياته الثقافية والقومية في تشكيل 
النظام العالمي، مادام خارج أرضية التحرك الفعال، ابتداء من هذه النظرة الدائرية المغلقة ،نظرة الهيمنة كبل والوجود المتوح ،لأوربا والغرب على ساحة تاريخ العالم"ب؛.

ويجد الباحث أن باحثي الغرب يعترفون بأسبقية مجموعات وظواهر غير متجانسة.. معظمها خارج القارة الأوربية ،وفي هذا القول اعتراف بحضور قبلي أو تكوينات اجتماعية غيربة ،ويقر الباحث انطلاقا من ذلك أن المستشرقين يعتمدون سردا متخبطا يزاوج بين العقل والخيال . كالحديث عن الحضارة الفرعونية وربطها بالجمال أو عن رومانسية ألف ليلة وليلة.... كبما يرضي العقل الثرقي، وفي هذا الأمر إنكار لتاريخية العالم في مجموعه ،فالاعتراف بالتاريخية هو إقرار بعراقة حضارات الثرق واستمرارها قرونا طويلة، مما يعني الإقرار لحضارة مصر الفرعونية أنها كانت منبعا للفلسفة اليونانية ،ومن ثمة فالإيمانية التوحيدية نشأت في أرض الثرق مع نكون الأنظمة الفلسفية الكبرى. وتطورت النظرة الاصطفائية التحيزية في التصنيف الاستبعادي الذي اعتمده الغرب ،حينما قسم العالم إلى أول وثاني وثالث، واحتكر التسمية الأولى بتعميمها على دول أوربا الغربية وأمريكا الثمالية الرأسمالية المتقدمة. .،ليتم تهميش العوالم غير الغربية واعتبارها مكونات هامشية عابرة ومرفوضة. وقد ابتدع "أنور عبد الملك" مفهوم "فائض القيمة التاريخي concept" الذي يذهب معناه إلى أن الغرب استطاع الحصول على مركزية حضورية بسبب نراكمية النهب والاستعمار مدة خمسة قرون أو ابتداء من عصر الاكتشافات البحرية ،حيث نتج عنه ما يلي:

الموجة الأولى من الغزوات، والنهب، والاحتراق ،جاءت لتضرب المنطقة العربية-الإسلامية اعتبارا من القرن التاسع أي منذ الحروب الصليبية، ونتكل العدوانية الحربية العنصرية الصهيونية الحلقة المعاصرة من هذه الموجة. 
الموجة الثانية، الموجة الأثد فتكا من الناحية البشرية، عصفت بالقارة الإقريقية ،وكان للنزف اللاحق الذي ترتب على تجارة الرقيق أعمق الأثر على إمكانات إفريقيا المعاصرة.

وجاءت الموجة الثالثة فدمرت الحضارات والمجتمعات الهندية في أمريكا الوسطى والجنوبية وأخضعتها للإمبراطوريتين البحريتين الإسبانية والبرتغالية.

ووصلت الموجة الرابعة والأخيرة إلى جنوب آسيا ولاسيما شبه القارة الهندية ثم جنوب شرق آسيا وأخيرا شرقيها"گ`،ن هنا نجحت أوربا في ضرب مركزية الثرق ونقاط قوته، وساعد فائض القيمة التاريخي على السيطرة على العالم من خلال القوة البحرية ،"بينما ساهمت تقنيات الاتصالات في تكثيف نقل فيض الأفكار والنظريات والمفاهيم من المركز إلى الأطراف المختلفة، وكانت النتيجة تكديسا فريدا من نوعه عند المركز بلغ ذروته في تركيز صياغة النظرية الاجتماعية والاتجاهات الفكرية الحديثة عموما بين أيدي مراكز الهيمنة الغربية، من هنا ،استحال على شتى الأطراف ـ آسيا وإفريقيا وأمريكا اللاتينية ـ أن تتطور إلا على وفق النهج الذي تقترحه وتفرضه فرضا مختلف المدارس الفكرية في الغرب المهيمن" ؛ويقدم الباحث دليلا على هذه النية المبيتة ،حيث يبين أن بعض دول الثرق بمجرد تخلصها من السيطرة الغربية المباشرة في القرن التاسع عشر ،شهدت نهضة معتبرة في العالم. وانطلاقا من هذا الرأي رفض الباحث دعاوى العولمة والانفتاح على الغرب لضمان التحديث، ودعا إلى الانفتاح بدل ذلك على الثرق، كما اعتبر في كتابه "القومية والاشتراكية" أن الماركسية لا تعد سلاح تحرر لبلدان العالم الثالث في مجال الاقتصاد والسياسة فقط، وإنما أيضا وسيلة تحرر فكري من التأثثر الغربي.

إذن في مؤلفاته المختلفة "ريح الشرق · في أصول المسألة الحضارية ـ من أجل إستراتيجية حضارية" رفض أنور عبد الملك دعوى الانفتاح على الغرب للحاق بالركب الحضاري ،لما فيها من تحيز واضح للغرب وتحقيق لهيمنته وتأكيد لنفوذه، إذ الأمر يؤدي إلى التبعية والانحدار ،لذلك دعا إلى التوجه إلى الثرق وحضاراته والتخلص من النظرة الاتبهارية للغرب وإلى "التصركز على الذات وتعبئة طاقاتها لتحقيق 
ذلك التمركز وتعبئة الطاقات والقدرات لتكون قادرة على التصدي وتفتح الأبواب للإبداع الذاتي في العالم العربي" كاء هن هنا سعى إلى استبدال مركزية الغرب بمركزية عربية إسلامية.

وفي سعيه لحل أزمة المثقف العربي عرج على العلاقة المتكونة بين الأصالة والعصرية ،حيث أكد على ضرورة الخصوصية الحضارية التي يذهب معناها إلى احتفاظ كل مجتمع بخصوصية تؤثز عليه كويزداد تأثثرها كلما كان المجتمع عميق الجذور في التاريخ، ومن ثمة فالخصوصية تشهم في خلق جو من التجانس والتوحيد والألفة بين أبناء الوطن الواحد ،وتحصن الأمة ضد كل مؤثر خارجي يهدف إلى القضاء على هويتها الثقافية والحضارية.

وطالب "أنور عبد الملك" بالاستفادة مما سماه "الدوائر الجيوثقافية " ممثلة في منظمة "شنغهاي للتعاون" ومنظمة "آسيان لأمح جنوب آسيا"،ومنظمة "دول أمربكا اللاتينية" وبعض التجمعات الاقتصادية الصلبة مثل"ميركسور"......من أجل مواجهة أطماع الولايات المتحدة الأمريكية وإسرائيل في الثرق الأوسط،إذ نهضة العرب والمسلمين لن تتحقق إلا باستيعاب تجربة الثرق البعيد.

في كتابه "من أجل إستراتيجية حضارية" طرح "أنور عبد الملك" سؤال الصحوة والنهضة، وكيفية الجمع بين التجديد والتراث،إذ بين أن جذور الإشكال تمتد إلى زمن مبايعة محمد علي رئيسا حتى احتلالم

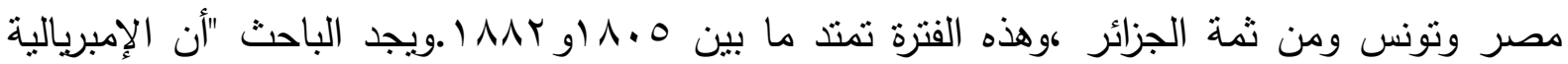
ذات نظام اقتصادي · سياسي لخدمة هدف حضاري لسيطرة الحضارة الغربية على شعوب وقوميات الشرق وليس نهب مواردها الاقتصادية فقط. ويرى أن الهدف تجلى في العديد من الاستعارات المتصلة على رأسها الحروب الصليبية ،ثم الموجهات الاستعمارية التقليدية بين القرنين الرابع عشر والتاسع عشر " ع

ويوضح في موضع آخر من ذات الكتاب أن الطرح المقدم من قبل صموئيل همنتغتون حول صدام الحضارات تجاهل أي مكونات حضارية قبلية، وراح يسرد تشكيلة الحضارات سردا قيميا يعتمد فيه على 
معايير نستتد إلى مرجعية الفكر والثقافة والدين، وهذا ما أثار ردود فعل متباينة بين مؤيد ومعارض، فأما المعارضون فيتمنلون في مفكري الثرق الإسلامي والعربي ،والذين وجدوا أن هذا الطرح قائم على أحكام مسبقة وتحيزات كامنة في تصور الغرب للثقافات غير الغربية، وهذا مدعاة لتأجيج الحروب والصراعات، كما وجد "أنور عبد الملك "'أن مراكز الهيمنة الغربية لاسيما في الولايات المتحدة تدرك عمق وأبعاد أزمة المشروع الحضاري الغربي التي تتلخص في أن هذه المراكز المهيمنة كترفض تماما ـ بطبيعة الأمر . وجود مراكز أخرى في العالم اللاغربي، وعلى وجه التحديد في الثرق في آسيا حول الصين واليابان وآسيا الثرقية ،تسنطيع أن تقدم أنماطا أخرى من المشروع الحضاري بستطيع أن يجتذب اهتمام وتأييد

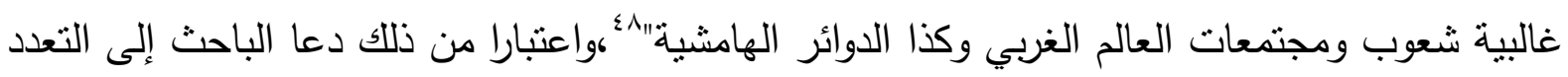
والحوار لا الصدام وإلى رفض المركزية الأحادية.

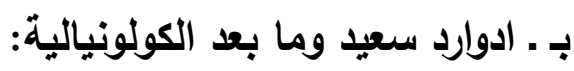

يعد إدوارد سعيد من أهم الباحثين في الخطاب الاستشراقي ،فإطاره المعرفي المتداخل سمح له بأن يطلع على المنظور الغربي للثرق عامة، ويقوم بمساءلته ومواجهة تتميطاته الجاهزة حول الثرق أو التمثيلات الخطابية المتحيزة ،"ويستكثف عمل سعيد ،بما ينطوي عليه من صرامة، المسائل النقدية المتعلقة بالتمثيلات الثقافية عبر تعرية التغيرات الابستمولوجية التي حدثت تحت ثأثثر الكولونيالية، والاستشراق ،والقومية ورهاب الأجانب" "حيث ،حيث وضح في كتاب "الاستشراق" كيف أن المعرفة الغربية تحكمها تحيزات واضحة للسلطة والبواعث السياسية الغربية وهذا ما يجعلها تبتعد في مضمونها عن الموضوعية الأكاديمية، ومن هنا وجد الباحث أن الثرق تحول إلى صنعة لغوية غربية في خطاب الاستشراق،إذ تدخلت المرجعية الاستعمارية والإمبريالية الأوروأمريكية في هذه الصياغة تحقيقا لمصالحها، وأطلقت الأحكام الانتقاصية وأنتجت عن الآخر الصور النمطية التبخيسية من أجل نسويغ اختراقه يقول"إنه الوعي الجغرافي السياسي المبثوث في النصوص العلمية والاقتصادية والاجتماعية والتاريخية 
واللغوية، وهو تطوير تفصيلي ليس فقط للتمييز الجغرافي الأساسي ...بل أيضا لسلسلة كاملة من المصالح التي يستعين في تحقيقها والحفاظ عليها بشتى الوسائل ...وهو في ذاته إرادة معينة أو نية معينة ،أي إنه ليس مجرد تعبير عن الإرادة والنية، لتفهم ما يبدو بوضوح عالما مختلفا(أو عالما بديلا وجديدا) وللسيطرة عليه في بعض الأحيان والتلاعب به وضمه إليه، وهو قبل كل شيء، خطاب لا يرتبط مطلقا بعلاقة مباشرة بالسلطة السياسية السافرة وموازية لها، لكن ذلك الخطاب يأتي غلى الوجود ويحيا في إطار التبادل المتقلب مع شتى أنواع السلطة، فيتتكل إلى حد كبير من خلا مبادلاته مع السلطة السياسية...والسلطة الفكرية...والسلطة التقافية.. والسلطة الأخلاقية.."•.من هذا المنطلق تلتقي عدة ميادين في الاستشراق حسب الباحث، منها العلاقة التاريخية والثقافية بين أوربا وآسيا، والنظام التدريسي العلمي الغربي، وأيضا كل الصور والتمثيلات المتخيلة والصور والتحيزات الأيديولوجية الكامنة في النظرة إلى الثرقهو" القاسم المشترك بين هذه الجوانب الثالاثة من الاستشراق هو الخط الفاصل بين الثرق والغرب وهو ،كما ،جادلت ،حقيقة من صنع البشر أسميها الجغرافيا المتخيلة، أكثر من كونه حقيقة طبيعية"اه. من هنا أصبح الاستشراق مصنوعا "من ترابط عدد من الخطابات التي تتصادم على الدوام بعضها ببعض منتجة علما قادرا على الاحتواء، حافزه الأساس استخدام المعرفة والسلطة للوصول إلى

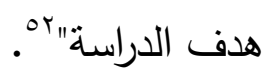

إذن فالمستشرق صار ينظر إلبه من موقع البطولة في عالم الغرب،إذ اضطلع بمهمة إنقاذ الثرق من الغموض والاستلاب والغرابة، ومن هنا فهو يعمل "على إعادة نتكيل وبناء اللغات والأعراف وطرق التفكير، وعلى استعادة الثرق القديم من خلال تقنيات استشراقية محددة في المعجمية وقواعد اللغة، والترجمة ،وفلك الشيفرات الثقافية، وعن طريق إعادة بناء وتشكيل الشرق الكلاسيكي من خلال أدوات العلوم الإنسانية" كه، ليصبح الثرق عنده موضوعا للمعرفة الأنثروبولوجية والفلسفية ،لذلك عرفه بأنه "نوع من الإسقاط الغربي على الثرق وإرادة حكم الغرب للشرق" ".ويخلص "إدوارد سعيد" إلى أن المسنشرقين في نظرتهم إلى الثرق يشتركون في عدد من الثوابت أهمها: 
" (. النعرة الجوهرية: حيث يقدم الغرب والثرق على أساس أنهما جوهران منفصلان ومتمايزان، كل له خصائصه الأصلية الثابتة، وهذا التمايز يضفي إلى تراتبية قيمية، إذ تنثل العقلانية والتطور والتحضر . •جوهر جماعة ، وأما نقيض هذه السمات كالروحانية واللاعقلانية والتخلف فتمثل جوهر الجماعة.

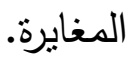

r. التعميم :إذ تكفي معرفة الجزء للإحاطة المعرفية بالكل.

r. التتميط :حيث يتم إضفاء خصيصة واحدة من خصائص الجماعة على الجماعة كلها . ع. الجمود: نسلب زمنية عالم الثرق أو تاريخيته، وهذا ما يجعل منه صورة للثبات والجمود ،حيث لاحياة

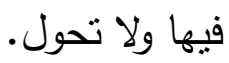

ه. التقرد :فالثرق يتأسس على اعتبار أحادي(دين واحد ومجتمع واحد وعقل واحد وثقافة واحدة..) T. الثقافوية :يتم تفسير سلوك الثرقيين وأفكارهم ونمط عيشهم على أساس مبدأ تفسيري واحد هو "ثقافتهم" ،هذه الثقافة يتم اختزالها في عنصر الدين بالدرجة الأولى".

وينتهي سعيد إلى ضرورة الحذر من أن يساهم الثرق في تشريق ذاته أو التمنل بالاعتبارات المستبطنة في الخطابات الاستشراقية..،إضافة إلى أنه لا يجد في الاستغراب حلا وجوابا عن الاستشراق، لأنه مجرد انفعالات تؤكد على القسمة الجوهرانية للعالم(شرق/غرب)،إذ سيكون وجه الاسنتراق الثاني مجرد رفع معنوي للطرف الدوني فقط، وهذا ما يجعله عاجزا عن إنتاج أي معرفة حيادية عن الذات وعن

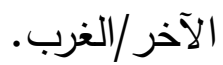

وبسبب مرحلة ما بعد الحداثة صار النظر إلى التاريخ من موقع ما بعد الكولونيالية، وعرف هذا النوع من الكتابة التاريخية أوجه مع فوكو ورولان بارت ودريدا، حيث حاولوا استتطاق العلاقة بين أنظمة السلطة والحقيقة التي تتحدد في إطار تاريخي ،كما حاولوا معرفة ما وراء اللغة ،إذ اللغة تقوم بصياغة 
الواقع صياغة مؤدلجة ومن ثم تحدده مسبقا ،لتكون الأثياء منجزات لغوية أو أبنية نصية/لسانية، وهذا ما يبرر عدم براءة التاريخ، إذ بشكل عام يمنل حركة سردية غير بريئة ،تتخل في تشكيلها المرجعيات

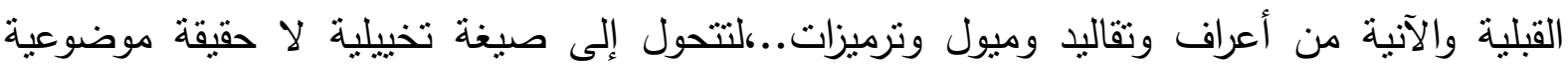
محايدة ،لذلك فالكتابة التاريخية لا تخلو من تحيز أو تحريف ،وهنا تتتفي الحقيقة الموضوعية "وربما كانت هذه الأسئلة الاستقصائية متصلة بالتيارات المعاصرة في التقكير، التي قادت إلى الجدل المحتدم حول وثوقية الكتابة التاريخية. فضلا عما أنتجته من أرضية تتافسية يتجه فيها النقاش حول مقترب مفهومي للتاريخ .إنه العصر الذي نوافق فيه التاريخ مع عمليات إنتاجه الخاصة"ه.

لكن ما نلاحظه أن الحكم فيه نوع من مجانبة الموضوعية، فكل ثقافة حال تموضعها في شكل مركزي فإنها ستمارس عملية طمس للثقافات الأخرى في سبيل الحفاظ على الريادة الموضعية عالميا ،إضافة إلى التعميم حال الحديث عن قضية استقبال ثثافات مغايرة ،إذ يجعل القاعدة العامة التي تحكمه وتصبغ آلياته :التتويه والتحويل والتزييف ،وفي هذا مغالاة واضحة تدفعه "إلى مواقع قريبة جدا من الذاتية النسبية في نظرية المعرفة ،فيذكر ،من حيث المبدأ إمكان تحصيل أية حقيقة موضوعية أو علمية بين الثقافات الأخرى، ولاسيما إذا بدت غريبة وبعيدة ومغايرة .لذلك لا يبقى أمام أية ثقافة من النقافات عند استقبالها لثقافة أخرى سوى عمليات التصور والتخطيط والاختزال الخ، دمع كل ما يرافق هذه العمليات من تثوهات وتعريفات وتزييفات وتحويلات تقرضها بالضرورة الثقافة المتلقية على واقع الثقافة المغايرة وعلى أصولها وماضيها وحاضرها" "جهات.

ولكن على الرغم من أن القول بزيف جميع الروايات التاريخية حول الماضي فيه شيء من التعميم الذي يجانب الصواب، إلا أنه يؤكد صدق الطرح الذي يعد أن معظم الكتابات الأوربية التي تم صياغتها محكومة بمصالح سياسية ورؤى أيديولوجية كترافقت مع النرجسية الاستعلائية والنظرة العنصرية التي 
تأصلت في مخططاتهم السياسية، وهذا ما يجعل هذه الكتابة التاريخية ما بعد الكولونيالية في سعي دائم نحو تعرية أيديولوجيا الاصطفاء المنغلقة وزعزعة وثوقيتها.

\section{جـ ـ حسن حنفي والاستغراب:}

حاول الباحث والمفكر المصري "حسن حنفي" أن يقدم منظورا مغايرا يتصدى به لمفهوم الاستثراق التحيزي ،حيث انتقل من العلاقة المتشكلة بين الأنا والآخر ليكثف عن التباساتها الأيديولوجية، حينما تصبح التراتبية مشكلا بسبب خلق التمايز بين صورة الأنا الغربية الموهومة بتضخماتها وصورة الآخر في منظور هذه الأنا والمتجهة نحو الأبلسة و التقزيم والانتقاص والدونية، من أجل ذلك اقترح تأسيس علم سماه"بعلم الاستغرابOccidentalism،والذي يحاول التصدي إلى التغريب westernization "الذي امتد أثره ليس فقط إلى الحياة الثقافية وتصوراتتا للعالم وهدد استقلالنا الحضاري بل امتد إلى أساليب الحياة اليومية ونقاد اللغة ومظاهر الحياة العامة وفن العمارة" لهاه.

ويقدم حسن حنفي تعريفا للاستغراب مركزا على هدفه وغايته فيقول :"الاستغراب الوجه الآخر والمقابل بل والنقيض من الاستشراق ،فإذا كان الاستشراق هو رؤية الأنا(الثرق) من خلال الآخر (الغرب) يهدف علم الاستغراب إذن إلى فلك العقدة التاريخية المزدوجة بين الأنا والآخر ،والجدل بين مركب النقص عن الأنا ومركب العظمة عند الآخر "هoويكون الأمر بتحويل الذات من موضوع للاراسة إلى دارسة من أجل القضاء على الإحساس بالنقص والدونية أمام الغرب.

إذن فالآلية هنا تعتمد الازدواج في مهنها ،إذ بقدر ما تحاول القضاء على التحيزات الكامنة في تصورات الذات الغربية عن الآخر المختلف ،فهي في الوقت ذاته تعلي من قيمة الأنا الثرقية وذللك بتحويلها إلى فاعل له القدرة على صياغة الوعي وتأطيره بما يراه انعطافا نحو الموضوعية والتبادل المعرفي الحر •ورغم ذللك نجد أن الهدف الذي ينوخاه الاستغراب ليس الحوار مع الغرب، وإنما القضاء على عقدة النقص ،وذلك من خلال التصدي إلى المركزية الغربية ،والأمر يتحقق بمحاولة التعرف على لى لع 
كيفية تموضع الوعي الغربي في مركزية واضحة عبر التاريخ الحديث، إذ يحاول المقترح الوقوف في وجه الآخر وثقافته من أجل ردها إلى حدودها الطبيعية بعد أن شملت دولا أخرى من خلال الاستعمار الذي كان الاستشراق واحدا من آلياته.

تتحدد مهمة علم الاستغراب في محاولة القضاء على المركزية الأوربية، ابتداء من تحديد الكيفية التي تموضع فيها الوعي الأوربي في إطار مركزي متعالي في فترات تاريخية عديدة، ومن هنا بسعى هذا العلم إلى رد ثقافة الغرب إلى حدوده الموضعية الطبيعية بعد أن انتشر بفعل الاستعمار خارج هذه الحدود •إضافة إلى كثف تحيزات الخطاب الغربي ودعوى العالمية التي تفترض في المنجز أن يكون غربيا. عاكسا لرؤيته حتى يعمم بصفة العالمية ،نفيا لسمة الاختلاف والتتوع وقضاء على الثقافات المحلية، ومن ثم خلق تتميط أحادي جاهز يعمم على كل الثعوب ،ليتم إغفال كل آخرية تحاول أن ترسم انوجادها الخاص مزاحمة المركز ،وكذا التعدد في خلق تمثيلات خطابية غير بريئة تهميشية وتبخيسية لهذه

إذن فعلم الاستغراب حاول القضاء على هذا التباين الأيديولوجي بين المركز والأطراف على مستوى الثقافة والحضارة، وسعى إلى القضاء على هذه الرؤية الذاتية المتحيزة التي غذت الخطابات الغربية باعتبارات عنصرية تقدس الذات ونتوه الآخر وتصوغه صياغة منطرفة، ولو أن "الحبيب الجنحاني" يجد في خطابه تعبوية واضحة ،إذ يقول :"ما يبشر به الأستاذ حنفي في كتابه مقدمة في علم الاستغراب لدراسة الغرب لتحرير الأنا من عقدة الخوف منه، والانبهار به،فهو أمر نظري يندرج ضمن خطابه التعبوي المسيس ،فالمجتمعات العربية الإسلامية عاجزة عن دراسة مشاكلها نتيجة للتخلف ،ولا مناص لنا من الاعتراف بحقيقة مرة، وهي أن الدراسات الجدية عن قضايا المجتمع العربي الإسلامي ما تزال تصدر حتى اليوم في الغرب ،وجل ما يصدر في العالم العربي عن المجتمع الغربي ضعيف، ويكاد يكون تلخيصا للاراسات الغربية، وهو في بعض الحالات تلخيص مشوه مبتور"هوه. 
ونحن نلاحظ أن مصطلح" الاستغراب" يحوي منطقا هجوميا ،كما أن "اثتقاق لفظة الاستغراب على نمط كلمة الاستشراق محاكاة لها أنكاء عليها وهو تتاقض من جانب من يريد أن يتحرر من المحاكاة ويثبت

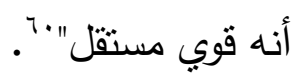

\section{د. عبد الله إبراهيم والكثف عن المركزيات:}

من أهم الباحثين الذين بحثرا في إثنكالية التحيز الأيديولوجي في الخطابات الغربية والعربية على حد السواء ،الناقد والمفكر العراقي "عبد الله إبراهيم" ،والذي اهتم بالكثف عن علاقة الأنا والآخر وما بسيج هذه العلاقة من اعتبارات مركزية، تجطلها عبارة عن جملة انطباعات لا تخلو من تهويهات إيديولوجية ،بسبب تحول الذات نظرا لتعاليها إلى صورة منسجمة في الخطاب حدودها التعالي والفوقية والنقاء ،بينما المغاير المختلف فيتحول إلى اعتبار اختزالي يعكس صورة مشوشة ،لذلك فهو يحمل معاني الوحشية والضدال والتخلف...6وقد قدم على إثر ذلك تعريفا للتمركز الظاهر في شكل مضمرات خطابية بقوله:

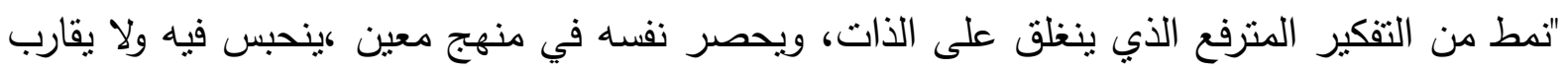
الأثنياء إلا عبر رؤيته ومقولاته. ويوظف كل المعطبات من أجل تأكيد صحة مقولاته" ".

إن ما يلاحظ على هذا التعريف هو اعتماده على المدرك العقلي والمتخيل المحكوم بأيديولوجيا الاصطفاء في الوقت ذاته ،ما يجعل أمر ضبطه صعبا لكون التخييل ينافي في جوهره عملية التفكير السليم ،ومن هنا فالعملية تتطوي على تصنيف استبعادي، بحكم أنها تتجاهل كل من يخرج عن إطار جماعة مركزية محددة، حيث "ينسج المركز لنفسه صورا نقيضة متل العقلانية والإنسانية والتقام والعلم في

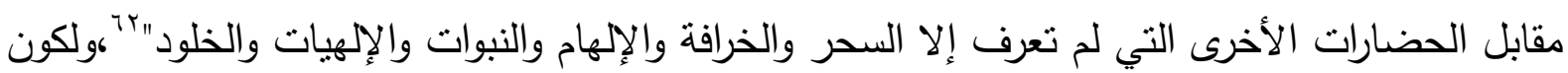
هذا النسج يتموضع داخل المرويات السردية التي تعتمد الانتقاء ،والازدواج في رسم حدود الذات والآخر ، فإنه في موضع آخر من نفس الكتاب يقدم تعريفا مغايرا للتمركز ،حيث يقول :"نوع من التعلق بتصور 
مزدوج عن الذات والآخر ،تصور يقوم على التمايز والتزاتب والتعالي يتتكل عبر الزمن بناء على ترادف متواصل ومتماتل لمرويات تلوح فيها بوضوح صورة انتقيت بدقة لمواجهة ضغوط كثيرة" ب". ولربما التعريف الثاني أكثر دقة لكونه انتقل به من اعتباره نمطا من التفكير والذي يفترض العقلانية والموضوعية ،إلى النظر إليه على أنه متعلق نفسي أو تصور ذاتي خالص، يفترض الارتكاز على الأنا ومن ثمة مجانبة العقلانية والموضوعية في الطرح.

وعلى ضوء مصطلح التمركز عدد الباحث إلى قراءة الظواهر الإنسانية، من أجل الكثف عن التمثيل المؤدلج وإكراهات الصياغة الأنوية، فكثير من المصطلحات تركيبة غربية حملت في مضمونها اعتبارات الآخر الغربي ،لتقصي محددات الهوية وتعدل منظورها بما يوافق الرغبة في السيطرة والاحتكار ، ومن ثم فصصطلح "الغرب" الذي تحدد أكثر مع الكثوفات الجغرافية الكبرى والثورة العلمية والفكرية ،هو تأكيد لهذا المنظور الإقصائي،إذ نم معهما تهميش الثعوب الأخرى ،واعتماد معايير الذات في وسم الإنجاز بأنه بداية للزمن الأوربي • في حال الكثوفات الجغرافية ـ كوبداية للتحضر ونشر النقدم . في حالة الثزة الفكرية والعلمية ـ ،لذلك تم تجاهل الزمن القبلي للثعب الأصلي في الحالة الأولى وتم تجاهل نبة الاستعمار وما تبع ذلك من قتل ووحشية ،كما تم تجاهل المعايير المغايرة لوسم أب دولة بالتقام، ومعها بدأت عملية التطهير العرقي تحت مسمى" تمدين الدول المتخلفة" ونشر قيم التقام كما هي منجز غربي بحت، على الرغم من "أن محاولة تعميم هذه القيم، هو فعل لا أخلاقي إذا ما أصبح مشروعا يستتد إلى القوة

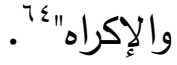

وجد عبد الله إبراهيم أن أيديولوجيا الإقصاء كامنة أيضا في الخطابات الفلسفية الغربية، حيث تركب صورة مشوشة للآخر وصورة حدودها النقاء للذات ،وعلى إثر ذللك "علمتتا التجربة الغربية درسا بليخا في مجال كيفيات تغييب وعي الإنسانية المؤمنة بذاتها ،كمقدة لطمس هويتها. فتبدو في انطباعات الفكر الإنساني على غير جدارة بالاستقلالية أو الاستحقاقية الحضارية"هoفمن نظرية الكيوف الأرسطية إلى هلى 
فلسفة هيغل وصولا إلى الخطابات الاستتراقية وغيرها ،كلها احتفاء بالأنا في صيغة تعظيم وتهميش وانتقاص للآخر المختلف،ودعوة إلى إيصاله لمصاف التقدم والنطور عن طريق سلوك نفس الطريق التطوري الغربي ،واعتماد نفس قيمه ،ولن يكون الأمر إلا بواسطة الاختراق والاستعمار ،إذ كل حملة

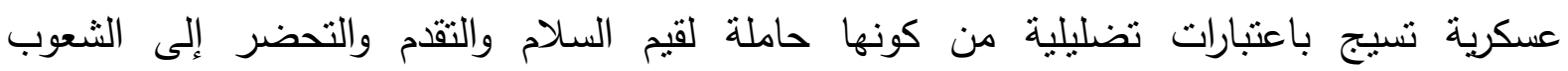
المتخلفة.....ولنتأمل هذا النص الذب يكثف فيه عبد الله إبراهيم عن المضامين الأيديولوجية التحيزية للذات في فلسفة هيغلى ،حيث يقول "التفكير الديني الذي هو تعبير عن الروح المطلق، هو ممارسة

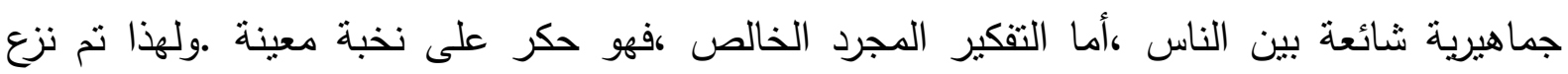
الصورة الحسية الدجازية عن الأديان، وتم تأمل مضامينها الفكرية، فإن الديانة المسيحية هي الديانة الوحيدة والصحيحة صحة مطلقة"“".ومن هنا فالإقصاء يطال جميع الثقافات في مقابل احتفاظ الذات الغربية/المسيحية بمركزيتها ،ناهيك عما احتوته الخطابات الاستشراقية من منظور تحيزي ،هدف إلى هلى إعادة ترتيب العلاقة التراتبية بين الأنا والآخر، ليصبح ضربا "من الممارسة الفكرية التي اقتضتها حاجة العقل الغربي لأن يشمل ب"كليته" ،المعطيات النقافية لـ"الآخر"، وإعادة إنتاجها ،بما يجعلها تتدرج ضمن

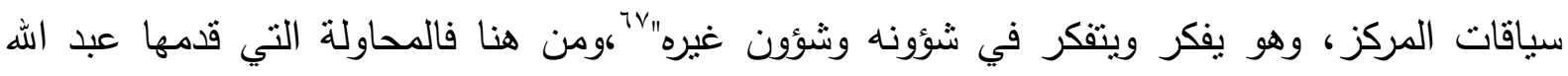
إبراهيم تتببه في مضامينها دعوى الاستغراب المطروحة من قبل المفكر المصري "حسن حنفي" ،والذي اتجه نحو تعطيل مفهوم التمركز من أجل استبداله بمنطق الحوار والتفاعل واحترام المغايرة، حيث هدف إلى "قاك العقدة التاريخية المزدوجة بين الأنا والآخر، والجدل بين مركب النقص عند الأنا، ومركب

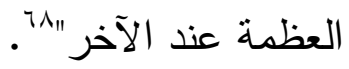

لم يكتق عبد اله إبراهيم بمثابعة ظاهرة التحيز في التمنيلات الخطابية الغربية، بل تعدى ذللك إلى الخطاب الإسلامي ،ممثلا في المرويات السردية القديمة التي مثلت الآخر تمثيلا غير برئ ،واصطنعت صورا تبخيسية في حقه، "فالعالم خارج دار الإسلام ،كما قامت تلك المرويات بتمثيله .غفل مبهم، بعيد عن الحق، وهو بانظظار عقيدة صحيحة لإنقاذه من ضلاله، ولا تخفى التحيزات الخاصة بذلك التمثيل 
،فهي مكثوفة ،وواضحة ، وكانت صورة الآخر الدونية مثار قبول واحتفاء في كثير من الأحيان لاى المؤرخين والجغرافيين، ولم يجر · في حدود علمنا . نقد معمق لها، ولا كثف التنميطات الثقافية الجاهزة للآخر "9"ولربما مصطلح" دار الإسلام" هو تأسيس لهذه النظرة غير المحايدة، والتي تتوخى نركيب صورة حدودها الالتباس للآخر، حيث يتم تهيشه اعتبارا من القيمية الدينية والنسق النقافي المهيمن ،لتطلق الأحكام الاختزالية ،وتتوارى الحقيقة وتحل محلها الصور النمطية الني تمثل صيغة عداء واضح ،"وبذلك أقصى كل المعاني الأخلاقية المقبولة عنده، واستبعد أمر تقبل النسق الثقافي له، فحمل الآخر ، من خلال تفسير خاص، بقيم رتبت بتدرج لتكون في تعارض مع القيم السائدة وبذللك اصطنع التمثيل تمايزا بين الذات والآخر ، أفضى إلى منوالية من التعارضات والتراتبات التي نسهل إمكانية أن يقوم الطرف الأول في اختراق الثاني، وتخليصه من خموله، وبوهميته، ووحشيته، وإدراجه في عالم الحق" ‘. ويقدم عبد الله إبراهيم حلا من أجل الكثف عن أيديولوجيا التمركز الإقصائية، يتمثل في سلاح النقد، والذي يعتبره قادرا على استجلاء التناقضات الكامنة في الثقافات المتمركزة، فهذا السلاح يسمح بالتعرف على مضمرات الخطاب، وتتبع كل الممارسات الملتوية من قبل المفاهيم الأيديولوجية، ما يساعد على التهيئة "لهوية نقافية جديدة قائمة على مسار متحول ومتجدد ومتتشعب الموارد من المنظورات والمكونات الثقافية المنتجة، أو المعاد إنتاجها في ضوء الثروط التاريخية للذات الثقافية" لهذه الهوية هي هوية الاختلاف التي تكون مركبة من عدة احتمالات ،لذلك فهي تحمل داخل اعتباراتها قابلية نقد الذات ونقد الآخر وبناء نفسها من جديد اعتبارا من هذا النقد المزدوج.

\section{هـ التحيز عند عبد الوهاب المسيري :}

ينبني المصطلح على التراكمية المعرفية والحضارية لعدد من الأشخاص يجمعهم انتقاء اتفاقي يتبع بتقنين معتد،، ولكون هذه الانتقائية ستعول على مرجعيات مختلفة فقد رفض "عبد الوهاب المسيري" أن تتم عملية نقل المصطلحات الغربية دون اجتهاد أو تمحيص ،فالنقل يتجاهل السياقات الحضارية التي 
أنتجت المصطلحات في ظلاها، وهذا ما يجعل أمر التفكير في إطار مفاهيمي يعتد المرجعية العربية أو التوليد من المعم العربي ضروريا ،لكونه يقضي على التحيزات الأيديولوجية الكامنة ويفرض تسميات

إلا أن العرب لم يهتموا بإنتاج المصطلحات وإطلاقها على الظواهر المستحدثة ،بل اعتمدوا على رؤى مستعارة وعقلية نطابقية ترتضي الاهتمام بما هو منجز غربي نقلا وشرحا واحتفاء، مهما أبدت من تعارضات سياقية وحضارية قد تخلخل المدرك العام أو الوعي الجمعي وتهدد مرتكزاته، لذلك فالتحيز يقتضي الاعتداد بآراء الذات وإقصاء كل المغايرات، وهذا ما لمح إليه ميجان الرويلي وسعد البازعي في مؤلفهما "دليل الناقد الأدبي" حينما عرفا التحيز بأنه :"ارتباط النقافة ومنتجاتها بالخصائص المميزة لتلك الثقافة، وبالظروف الزمانية والمكانية التي حكمت تثكل تلك الثقافة ومنتجاتها في مرحلة معينة كما أن من المقصود بلوغ التحيز حدا يجعل من الصعب فهم تلك الثقافة دون الوعي بجوانب تحيزها لنفسها ولظروفها المكانية والزمانية، بالإضافة إلى ما يخلقه من عوائق أمام نقل تلك الثقافة ومنتجاتها إلى حيز نقافي آخر دونما غربلة لبعض السمات الأساسية تخلصها من ذلك التحيز أو الخصوصية وتقلل من معدلهما"Yr. ومن هذا المنطلق أطلق المصطلح من قبل المسيري على مجال جديد يختص بدراسة ظاهرة إنسانية تعد من صميم المعطى الإنساني وترتبط بإنسانية الإنسان.

يتساءل عبد الوهاب المسيري :"هل يمكننا تخيل لغة دقيقة تماما، ترتبط فيها الدوال بمدلولاتها بشكل حتمي آلي كامل، لا يفصل بينهما فاصل ،ولا توجد بينهما ثغرات، بحيث يكون لكل دال مدلول

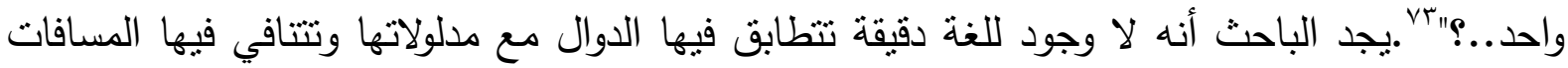
أو الثغرات التي تفسح المجال للتعدد ،ومن هنا فأي نص حسب ما براه مجموعة من الدوال المشيرة إلى لى مجموعة من المدلولات والعلاقات الخارجية من خلال علاقاتها الداخلية. وانطلاقا من هذا الأمر يتراجع المفهوم التطابقي لتتنكل مسافة اختلاف تفصل بين هذا الدال والمدلول ،إذ تتشكل هذه المسافة من 
الأحلام والأوهام والرغبات والأهواء والأفكار والمصالح التي تعمل على الفصل بينهما ،وهذا التعدد يضفي إلى الاختيار الذي يعني استبعاد احتمالات كثيرة، والتركيز على اختيار واحد ،ومن هنا يخضع الاختيار إلى اجتهاد الذات وهذا ما يجعل الأمر متضمنا صفة التحيز أثناء الاختيار .ويوضح الناقد حقيقة هذا الأمر بقوله: "وقد أدمنا تماما عملية نقل المصطلحات دون إعمال فكر أو اجتهاد، ودون فحص أو مهرد تمحيص .فققد الإنسان العربي الحديث القدرة على نسمية الأثياء ،ومن لا يسمي الأشياء يفقد السيطرة على الواقع والمقدرة على التعامل معه بكفاءة .أما من يدرك الواقع حق الإدراك ثم يصنفه حسب مقولاته، ويسميه أسماء تتفق مع هذا الإدراك أمكنه الحركة فيه بقدر معقول من الحرية ،إذ أنه سيراكم المعلومات داخل مقولاته وأطره هو ،مما قد يزيد من مقدرته على التتبؤ بمسار هذا الواقع ويحسن من مقدرته على

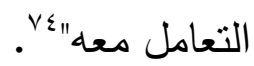

ويجمل المسيري أسباب صعوبة نقل المصطلحات في حقل العلوم الإنسانية والاجتماعية فيما يأتي: وجود كل دال ضمن تثكيل أو سياق حضاري محدد يستعمل لغة معجمية معينة. . وضع المصطلح على وفق منظور الذات فقط. آليات تمرير الخطاب الصهيوني لتحيزاته من منظور المسيري: يستتتج المسيري آليات خطابية من خلالها ينجح الخطاب الصهيوني في تمرير مفاهيمه وتحيزاته، وهي: 1".*. الترويج للاستخدام الاصطلاحي الديني في سياقات تاريخية زمنية ،منل :إسرائيل ـ أرض الميعاد . الثعب المختار ،إذ الشعب المختار يتحول في العقيدة اليهودية إلى جماعة دينية مختارة نظرا لتمسكها بعقيدتها، وليس كما هو رائج عن المعنى السياسي الحديث لكلمة شعب "ولكن الصهاينة جعلوا كلمة شعب تعني شعبا بالمعنى الحديث ولا يهم الإيمان بالعقيدة اليهودية من عدمه. والثيء نفسه يحدث مع 
الهجرة الاستنطانية (عالباه) والتي تعني الصعود والعلو، فكأن الهجرة إلى فلسطين بالنسبة إلى اليهودي

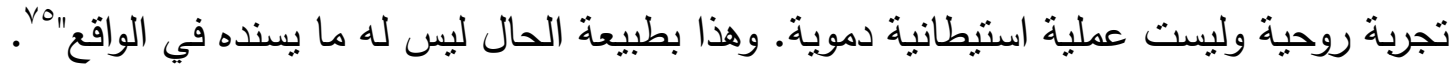
ץ*. تغييب الزمان والاحتفاء بمركزية المكان، حيث أرض الميعاد تصبح موضعتها خارج التاريخ ،ومنها يتسم الوجود العربي بالعرضية.

r". استعمال مصطلحات يحمل كل مصطلح منها معنيان: معنى معجمي ظاهر وآخر سيسي مضمر ،فمثلا القانون الدولي العام يمثل القانون الغربي عند الصهاينة.

ـ *. الإقدام على أيقنة بعض الدوال والظواهر والعبارات والتعامل معها بشكل مطلق، ومن ثمة لا يجوز مناقثتها ،من هنا تتحول إلى أيقونة حيث يتجسد الإله من خلالها ،وهذا يسمها بالانفرادية وعدم التكرار

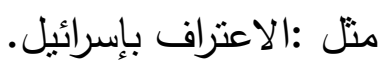

ه*. الترويج إلى بعض الصور النمطية مع استعمالات أو صياغات لفظية اختزالية تختزل الواقع ،منل :إسرائيل واحة الديمقراطية أو إسرائيل التي تمثل داوود الصغير الذي يقاتل طالوت الكبير .ومن هنا" تبدو

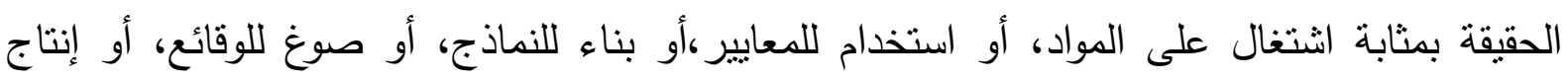

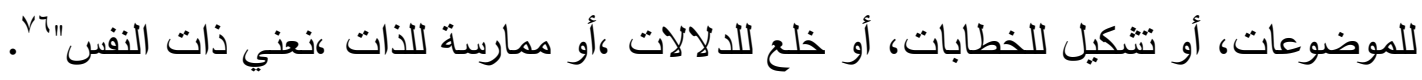

؟ ". "التأرجح المستمر والمتعدد بين أعلى مستويات التعميم والتجريد وأدنى مسنويات

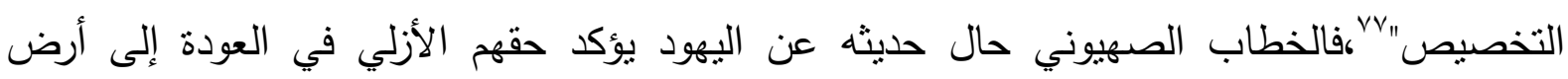
الميعاد ،بينما حال توجيهه إلى العرب يصاغ بشكل يساير مصلحتهم وذلك بالدعوة إلى نسيان الماضي وتقبل الأمر الواقع ،إذ توجه الحقائق نحو الاعتراف بحق اليهود في فلسطين إلا إنه وأثناء الدفاوضات بهات

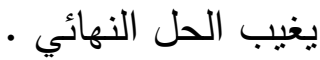


V**. استعمال مصطلحات تحيزية تغيب العرب على الرغم مما تدعيه من حياد، كالمستوطنين الذين وصفوا بأنهم رواد ،وهذه الكلمة تدل على أن أرضا خالية من السكان جاءها اليهود واكتشفوها، ليتم تغييب العرب من خلالكها.

1**. الخلط المفاهيمي بين الدوال، إذ تستخدم مفردات مختلفة للدلالة على معنى واحد ،منل: صهيوني ويهودي وإسرائيلي.

q*. استعمال دال واحد للدلالة على دوال مختلفة، منل: الشعب اليهودي الذي يشير مرة إلى الجماعات اليهودية غير المتجانسة جميعها، ومرة إلى الإسرائيليين.

• ا**. ويعد إخفاء مرجعية المصطلحات من أهم آليات الخطاب المراوغ والمخاتل ،إذ حال الحديث عن السلام يقومون بتغييب مضدونه الإقصائي لديهم والذي يهدف إلى الاستيلاء على الأراضي والاحتفاظ بالمستوطنات ،"وهذا الموقف يتضح حينما يحاول العرب الحديث عن الثرعية الدولية باعتبارها مرجعية المصطلح" (

ا'أ*. وأهم الآليات المراوغة إقصاء الأصول التاريخية للظاهرة والسياق التاريخي للمصطلح أو المفهوم ففثلا الادعاء بأن الصراع سببه عدم قبول العرب قرار التقيم أو بغض العرب لليهود، وأن المقاومة والتي تصبح في مفهوم الصهيونية إرهابا هي إقصاء العرب للآخر ورفضه ،"يهدف إلى تحويل الأنظار عن سبب الصراع الحقيقي أبي الاستعمار الصهيوني الاستيطاني الإحلالي الذي أتى بكتلة بشرية من الغرب ووطنها في أرض الفلسطينيين وطرد السكان الأصليين"

$$
\text { وللتغلب على التحيز . حسب المسيري ـ تستخدم آليات أهمها: }
$$

ا."محاولة الوصول إلى مصطلح أكثر عمومية من المصطلح الغربي ،بحيث يصبح المصطلح الغربي هو عبارة عن مثال نسبي خاص أو مجرد حالة لظاهرة إنسانية عامة"•،ويقدم مثالا عن هذا الأمر 
بمصطلح "الديمقراطية" إذ بدل الحديث عنها يمكن استبدالها بالحديث عن آليات المشاركة الجماهبرية في صنع القرار،لأن الديمقراطية شكل من أثنكال الششاركة كما هي "الثورى" أو "الاجتماعات القائمة لمجالس شيوخ القبائل.. ،من هنا تهتز مركزية المصطلح الغربي الواهمة، ويتحول إلى مجرد تركيبة لفظية وسط لغة إنسانية عامة.

r. الوقوف على الأبعاد المجازية في المصطلحات ومعرفتها، فمثلا مصطلح "رجل أوربا المريض "وصف غير موضوعي لحالة تاريخية بل ذو حمولة أيديولوجية تحيزية، إذ يعد استعارة لكون الدولة العثمانية شبيهة بالرجل المريض ،وهذه الدولة على طرف أوربا .من هنا فالمجاز تحيز حيث يقوم بترتيب الواقع على وفق منظور معين، وإدراكه يسمح لنا بمعرفة حدوده.

r. هناك مصطلحات عقائدية ومذهبية خاصة يجب عرضها أمام القارئ لمعرفة وجهة نظر الآخر .وقد

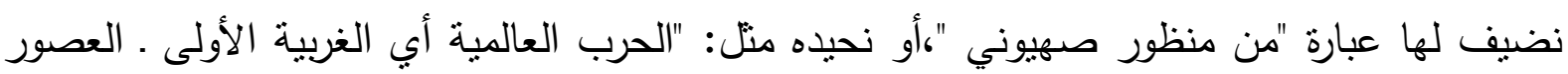

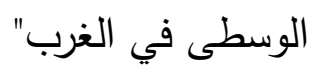

ع. استخدام التوليد والترجمة معا ،مثلا :استخدام "الرومانتكية" لوصف الحركة الفكرية الأدبية والفنبة التي سادت أوربا في القرن التاسع عشر بمواصفات محددة. .ثم نشير إلى ظاهرة مماثلة عندنا بنحت مصطلحات مقابلة لها لكنها تملك خصوصيتها مثل "الوجدانية". ويمكن تلخيص الآليات في النقاط الآتية:

ـ الاعتراف بوجود تحيزات كامنة في مختلف الخطابات ومن ثم ضرورة نقدها:

إن الوعي بالمثول التحيزي لتصوراتتا المنبنية على التخييل والاصطناع النمطي، يعد خطوة أساسية لإمكانية التجاوز ،لأنه يساهم في الوقوف على خفايا السلوك الإنساني المؤسس على نماذج معرفية 
يصوغها العقل البشري بطريقة غير حيادية، وذلك بالنظر إلى سياقات واقعية محددة .ليأتي النقد كخطوة ثانية ،حيث يهذف إلى ضرب مركزيات الخطاب. . الكثف عن اختلالات النموذج المعرفي الغربي ونقائصه:

فمعرفة النقائص حسب المسيري تساعدنا على التحرر من هيمنته، إذ لابد من إدراك عدائية هذا النموذج

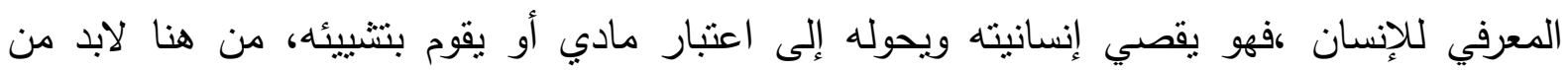
الوقوف على جوانب القصور المانلة في المجتمعات الغربية جراء النطبيقات المختلفة لهذا النموذج المعرفي، وكذا مسبباته ونتائجه، ناهيك عن دراسة الظواهر السلبية المصاحبة للحضارة الغربية والتي

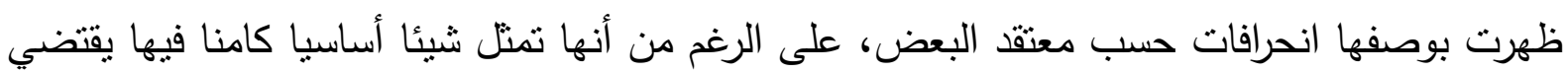
نفي الاستثنائية عنها منل:ا لإمبريالية والنازية..، وهذا كله سيؤدي إلى مزيد مراجعات للتاريخ الغربي وللملوم الغربية على اختلافها. . نقض مركزية الغرب والاففتاح على العالم كله:

إن النقد الموجه للحضارة الغربية لا يهدف إلى الانتقاص وإنما إلى الاستيعاب وفرز كل ما من شأنه

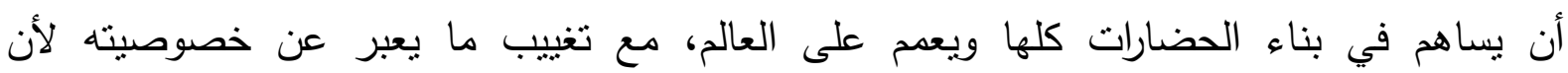
الخصوصية ميزة ذاتية وجب الاحتفاظ بها لا فرضها على العالم المنبني على التجاور والتعدد ،من هنا ولنفض المركزية الغربية وجب تجريد الغرب من صفة العالمية ،وذللك بعد معرفة أبعاد نتكل حضارته وظروف تموضعاته والمؤثرات الداخلة في تشكيله.

لتكون الخطوة الثانية بمثابة إجراء تكميلي للخطوة الأولى، حيث نقض المركزية يتبعه الانفتاح على الحضارات المغايرة والتي تم تغييبها وتهيشها مثل الحضارات الثرقية. . موهذا الانفتاح يساهم في تعديل المعرفة أو تعديل تصوراتتا ومدركاتتا التي تتوهت بفعل التحيز، ومن هنا يساعدنا على التخلص من 
التلقي السلبي ليكسبنا القدرة على نقد الخطابات التي ظهرت بوصفها حقائق مطلقة مدة من الزمن وحجبت عنا الحقائق الأصيلة أو المعرفة الموضوعية.

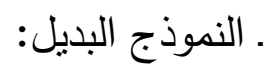

ويقتي هذا النموذج مراعاة خصوصيتتا الحضارية والانطلاق من مرجعياتتا الدينية، لذلك لابد من بناء نموذج معرفي منطلق من تراثنا وتأسيسه على القرآن والسنة والقيم الإسلامية ،لكن مع انتفاء النسخ والمطابقة الحرفية للاجتهاد القبلي، إذ لابد من الوقوق على القواعد الكامنة في اجتهاداتهم والبناء عليها لقراءة الموروث. وهذا النموذج ينطلق من الإنسان ،لذلك فهو توليدي غير نراكمي ولا مادي يقتضي فهم التتوع الإنساني والتعدد ،من هنا فهو ينشئ علما إنسانيا يحتفي بالاجتهاد ولا يركن إلى النهائية والحسم، كما لا يهدف إلى التحكم النهائي بالواقع نظرا لإدراكه محدودية المعرفة الإنسانية لذلك فهو لا بلغي لإني الثنائيات التي تعد انعكاسا لثنائية الخالق/المخلوق، الإنسان/الطبيعة. من هذا المنطلق يبحث هذا العلم في كل الأبعاد المشكلة للظواهر دون تحيز لبعد واحد، وذلك حتى يتم استخلاص أكثرها فعالية ،إذ ينتفي الاستباق أو التسليم المسبق، وهذا العلم يعتمد عدة مفاهيمية جديدة. واعنبارا من ذلك نصل إلى نظرية معرفية شاملة لا تقتضي التفسير النهائي للظواهر والأثياء ،بل تتأسس على النسبية. 
الخاتمة:

يمكن الإجابة عن الإشكال المطروح في مقدمة البحث من خلال الوقوف على بعض النقائص الواردة في هذه القراءات:

كل مرجعية تدعم الخطاب تجد تجلياتها فيه، مما يجعل الحديث عن مرجعية منفصلة عن الخطاب من قبيل المغالطة ،إذ يصعب الجزم بوجود خطاب نقدي مستقل.

ـ لم تسنطع القراءات المقدة أن تتحرر من المرجعيات المستعارة، إذ توسلت مناهج الغرب في كثفها لمضمرات الخطاب في الوقت الذي تدعي أنها تحاول تقديم قراءة محايدة بعيدة عن التحيز للمنجزات الغيرية .لذلك يمكن القول أن إدوارد سعيد مثنلا قد اعترف بهيمنة الآخر في الوقت الذي هدف إلى فضح أساليب هيمنته.

لم يستطع علم الاستغراب كما تصوره حسن حنفي أن يتحرر من النظرة المتحيزة ،إذ المستغرب ليست له القدرة على دراسة الغرب بمعزل عن أيديولوجيته وموقفه التاريخي ورؤيته الثقافية.

ـ قدم عبد الله إبراهيم قراءة جديدة أراد فيها الكثف عن تحيزات الخطاب، بوصفه منتجا ثقافيا نتذخل العديد من المرجعيات في صياغته، وعلى الرغم من ذلك لم يستطع التحرر من المرجعيات المستعارة التي طالما دعا إلى ضرورة التخلص منها ،فقد استخدم آليات غربية ومنهجا غربيا في قراءته للموروث، وهذا ما يفتزض عدم وجود نصوص نقدية محايدة.

• بالنسبة للمسيري: الاعتماد على ترسانة مفاهيمية كبيرة مرجعياتها ـ المذاهب والتيارات الاجتماعية والفلسفية ـ متعددة إلى حد التضارب، حيث أعيد تشكيلها بما يوافق ذوق المتلقي. وقد كان هاجسه الوحيد هو محاولة التخلص أو التحرر من فحل التحيز الكامن في المفاهيم الغربية المستعارة ،لكن هذا الهاجس النفسي لم يكن له ما يبرره في كل الحالات، إذ ليست كل المفاهيم الغربية تضمر دعوة إلى التبعية 
والتحيز خاصة إذا علمنا أن الحضارات والأمم تتبني على التراكمية التي تفترض الاستفادة من المعارف الإنسانية مهما اختلفت مصادرها، فالمسيري ذاته يستخدم بعض المفاهيم والمصطلحات المستعارة من فلسفات أعادت الاعتبار للإنسان في نقدهأي من الحقل الدلالي للمفاهيم الفلسفية والاجتماعية الغربية. كما أن السعي وراء التمايز النحتي كاستخدام تعبيرات "الأكثز تفسيرا" و"الأقل تفسيرا" بديلا عن الذاتية والموضوعية، قد لا تكون أكثر دقة من التي غيرناها، إذ تلك التعبيرات قد تكون ثقيلة لأن العقل العربي لم يتعود عليها. ـ المسيري لم يمارس النقد بشكل شامل ،إذ اكتفى بتفكيك مرتكزات الحضارة الغربية والنظر إليها باعتبارها حضارة مادية قائمة على فلسفة مادية حلولية علمانبة شاملة. ومن هنا غيب النقد الذاتي كما سماه علا الفاسي، أو النقد المزدوج على حد تعبير عبد الكريم الخطيبي، وهو ما حاول القيام به عبد الله إبراهيم

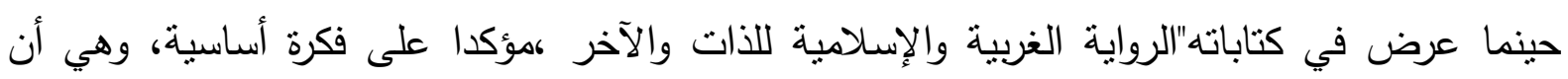
المركزيات تصاغ استتادا إلى نوع من التمثيل الذي تقدمه المرويات الثقافية (الدينية ،والأدبية ،والتاريخية ،والجغرافية ،والفلسفية، والأنثروبولوجية) للذات المعتصمة بوهم النقاء الكامل، والآخر المدنس بالدونية

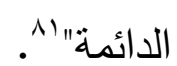

ـ تركيز المسيري على المنظور الحجاجي والروئية الدفاعية من خلال رده، صبغ مقولاته بالطابع الحجاجي المتميز بالقوة والتحرك النقدي في اعتبارات معرفية مختلفة ،إلا أن مقاومة الهيمنة قد تؤثز على الجهاز المفاهيمي، فعلى الرغم مما تميز به المسيري من نحت موفق ساهم من الناحية النفسية في تعزيز الثقة بالذات والتحرر من هيمنة الدتعارف عليه في الدراسات الإنسانية والاجتماعية ،وكذا محاربته على جبهات مختلفة إلا أن الأمر لا يخلو من نقائص. 
عبد الله إبراهيم: المطابقة والاختلاف المؤسسة العربية للاراسات والنشر /دار الفارس للنشر والتوزيع.

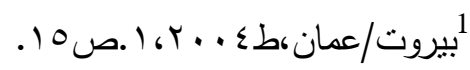

• ابن أحمد قويدر :المثاقف ة:دراسة في المفهوم والتداعيات مجلة شبكة العلوم التقنية العربية،العدد ـ (،ربيع

$$
.119 \text { ص.r... } v^{2}
$$

. دوني كوش :مفهوم الثقافة في العلوم الاجتماعية ،ترجمة :قاسم المقداد ،منشوارت اتحاد كتاب.

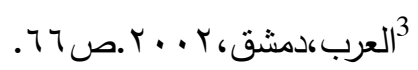

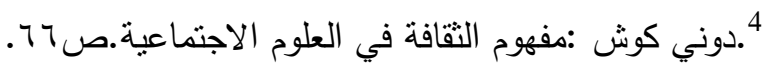

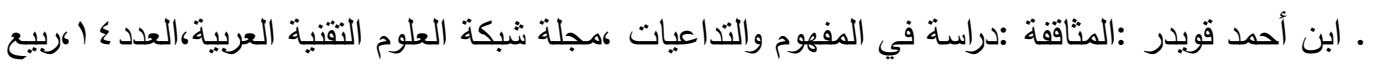

$$
\text { .Ir. r. r. . . } v^{5}
$$

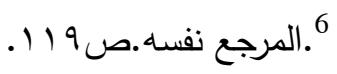

7

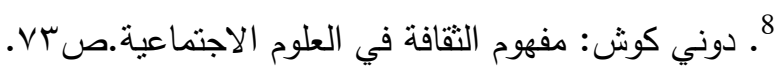

نادر كاظم :تمثيلات الآخر :صورة السود في المتخيل العربي الوسيط ،المؤسسة العربية للاراسات ناشرون/دار الفارس.

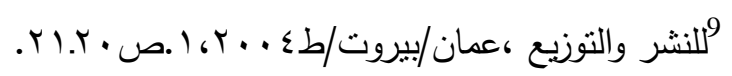

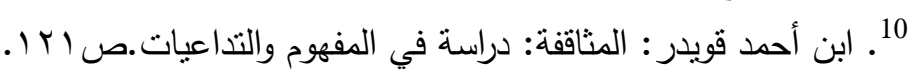

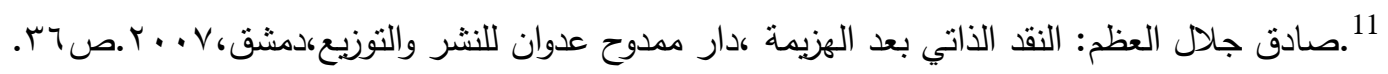

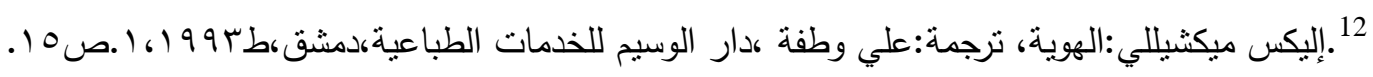

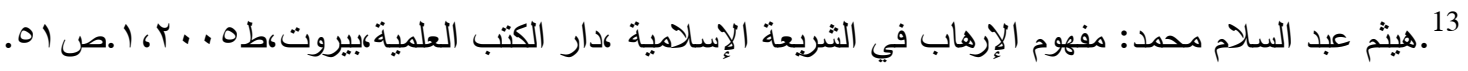

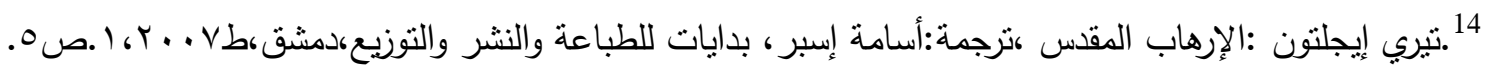

نعوم تشومسكي: الإرهاب الدولي ـ الأسطورة والواقع ،ترجمة :لبنى صبري، منشورات سينا.

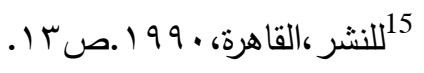

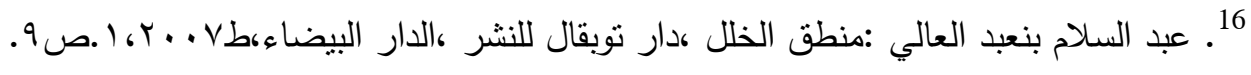

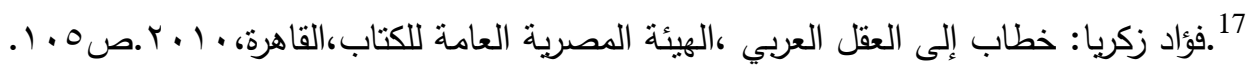

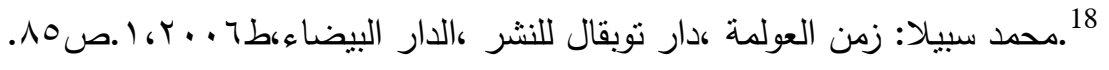

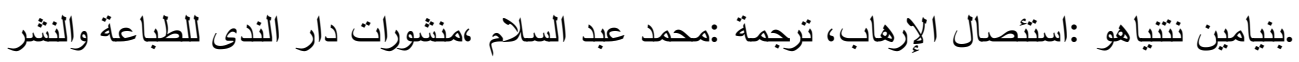

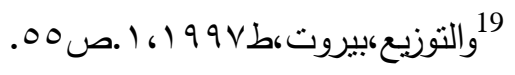




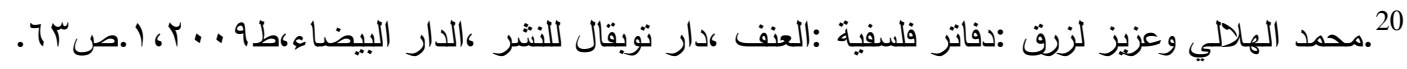

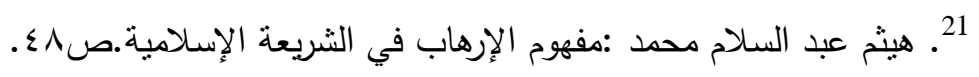

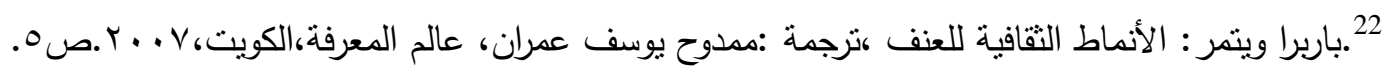
. 23 المرجع نفسه. 23 24. إدوارد سعيد: الثقافة والمقاومة ،ترجمة: علاء الدين أبو زينة، دار الآداب،صو9.9. . . 1.

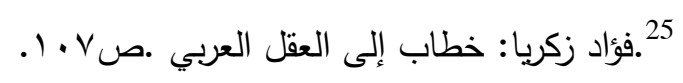

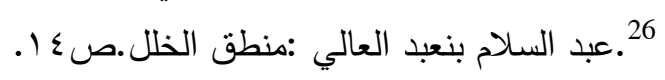

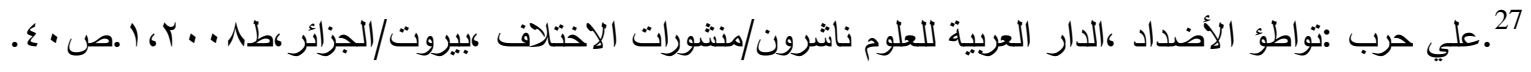

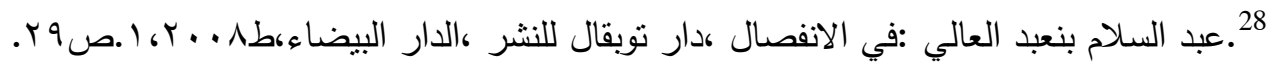

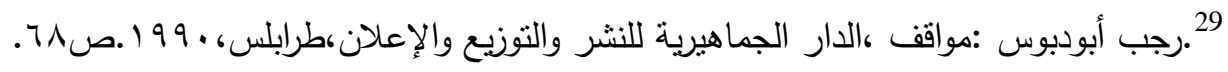

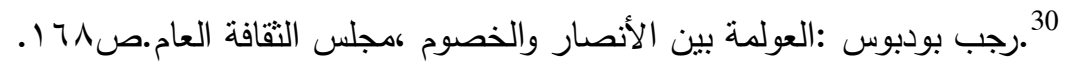

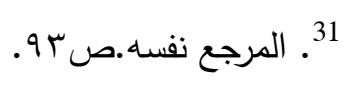

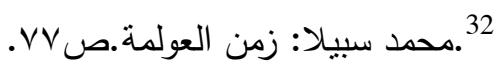

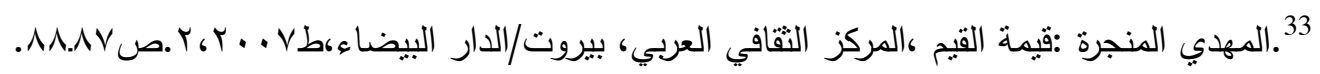

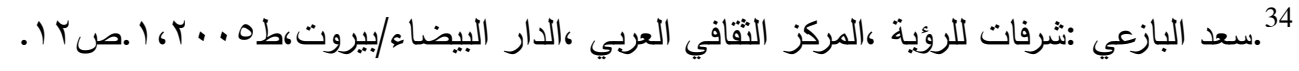

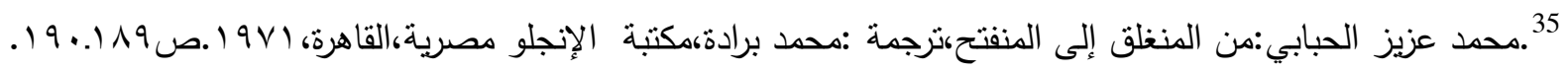

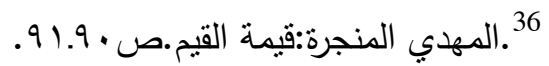

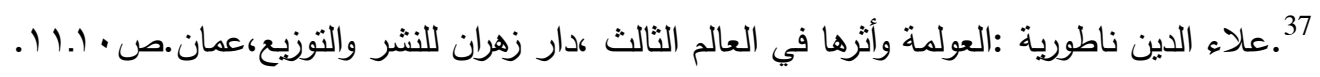

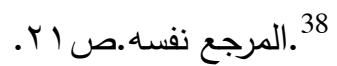

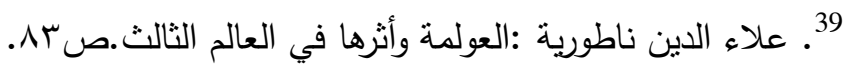

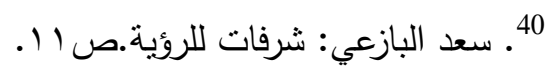

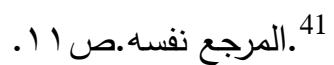

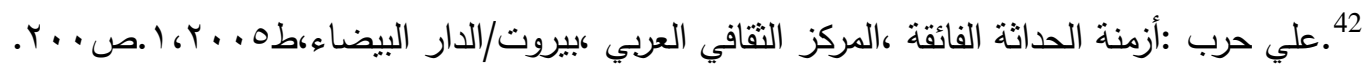

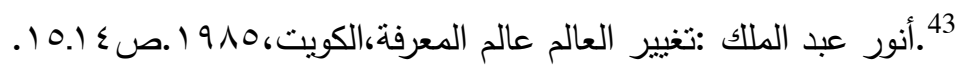

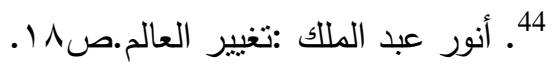
45. أنور عبد الملك :تغيير العالم.صو 194

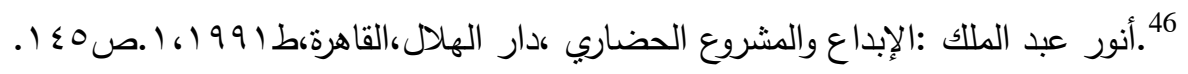


محمود قرني :مفهوم الخصوصية ليس عصيا على التفكيك وكل الأمكنة والتواريخ خاضعة للمساعلة ،جريدة القدس ،العدد.

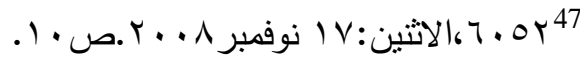
48

تشيلي واليا :إدوارد سعيد وكتابة التاريخ ،ترجمة: أحمد خريس وناصر أبو الهيجاء ،أزمنة للنشر.

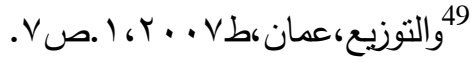

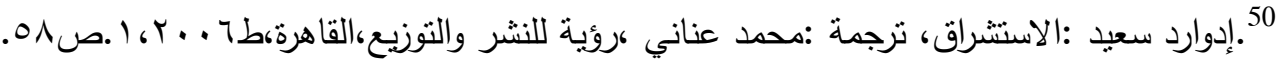

•إدوارد سعيد :تعقيبات على الاستشراق كترجمة :صبي حديدي ،المؤسسة العربية للدراسات.

$$
\text { 51 } 51
$$

52.إدوارد سعيد :تعقيبات على الاستشراق، .صس؟

•وليام د هارت :إدوارد سعيد والمؤثرات الدينية للنقاف ة،ترجمة :قصي أنور الذبيان ،هيئة أبو ظبي للنقافة والتراث ،أبو

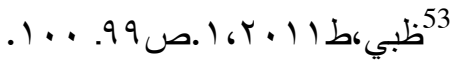

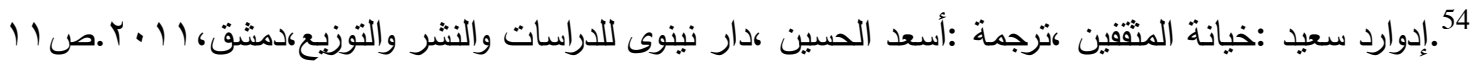

55 ـ إدوارد سعيد :خيانة المثقفين.صسئ.

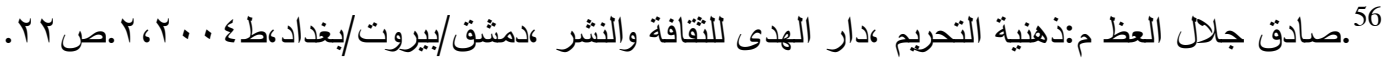

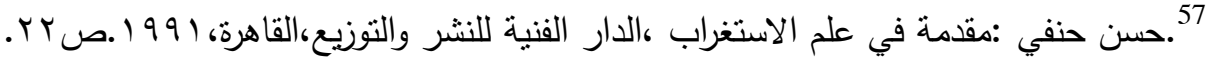

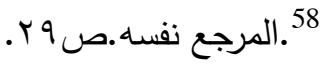

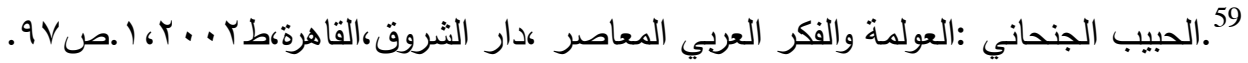

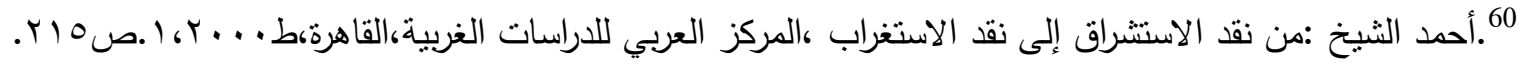

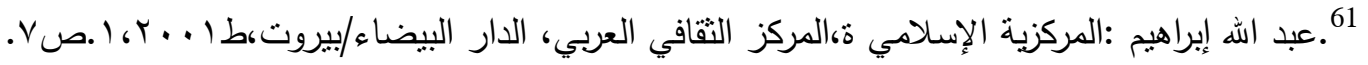
62.حسن حنفي:هل النقد وقف على الحضرة الغربية.ص V. 63

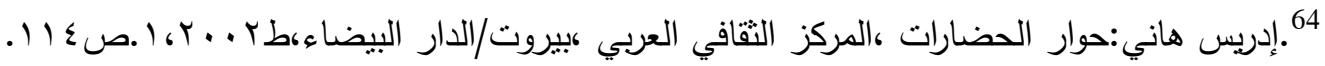

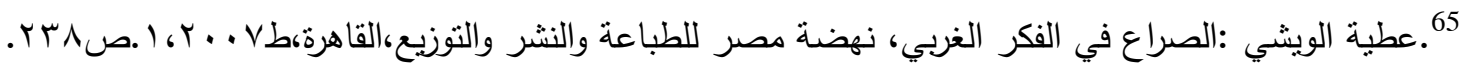

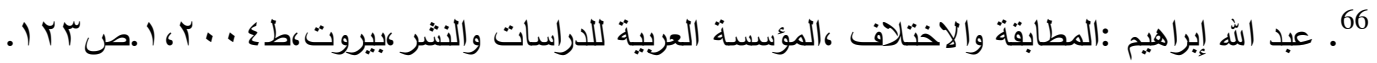

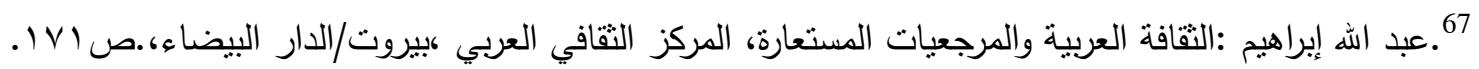
68.حسن حنفي :مقدمة في علم الاستغراب.ص اله 7. 69.عبد الله إبراهيم :المركزية الإسلامية.صن.7. 70 . عبد الله إبراهيم :المطابقة والاختلاف.ص إلهربه 10 


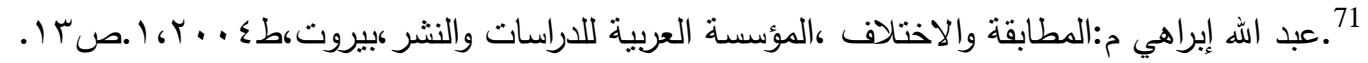

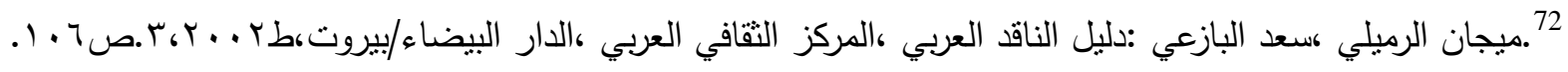

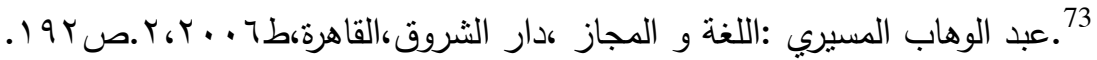

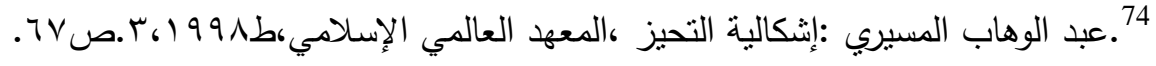

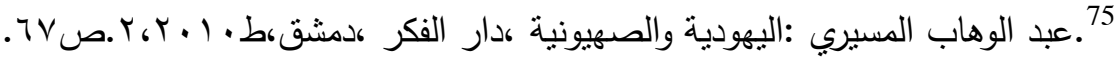

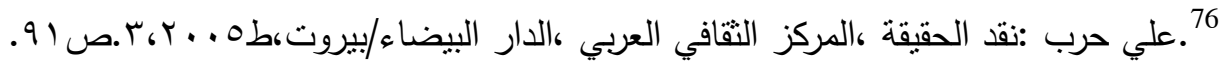
77 7. 79.

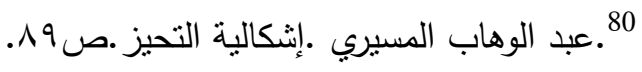

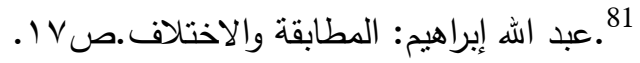

